\title{
Evaluating Health Co-Benefits of Climate Change Mitigation in Urban Mobility
}

\author{
Brigitte Wolkinger ${ }^{1, *}$, Willi Haas ${ }^{2,3}$ (D), Gabriel Bachner ${ }^{1}$ (D), Ulli Weisz ${ }^{2,3}$, \\ Karl W. Steininger ${ }^{1,4} \mathbb{1 D}^{1}$, Hans-Peter Hutter ${ }^{5}$, Jennifer Delcour ${ }^{6}$, Robert Griebler ${ }^{6}$, \\ Bernhard Mittelbach ${ }^{1}$, Philipp Maier ${ }^{2}$ and Raphael Reifeltshammer ${ }^{7}$ \\ 1 Wegener Center for Climate and Global Change, University of Graz, Brandhofgasse 5, A-8010 Graz, Austria; \\ gabriel.bachner@uni-graz.at (G.B.); karl.steininger@uni-graz.at (K.W.S.); mittelbach@gmx.at (B.M.) \\ 2 Institute of Social Ecology, Alpen-Adria University Klagenfurt, Schottenfeldgasse 29, A-1070 Vienna, \\ Austria; willi.haas@boku.ac.at (W.H.); ulli.weisz@boku.ac.at (U.W.); phqmaier@gmail.com (P.M.) \\ 3 Institute of Social Ecology, University of Natural Resources and Life Sciences, Vienna, Schottenfeldgasse 29, \\ A-1070 Vienna, Austria \\ 4 Department of Economics, University of Graz, Universitaetsstrasse 15, A-8010 Graz, Austria \\ 5 Department of Environmental Health, Center for Public Health, Medical University of Vienna, \\ Spitalgasse 23, A-1090 Vienna, Austria; hans-peter.hutter@meduniwien.ac.at \\ 6 Austrian Public Health Institute (Gesundheit Österreich GmbH), Stubenring 6, A-1010 Vienna, Austria; \\ jennifer.delcour@goeg.at (J.D.); robert.griebler@goeg.at (R.G.) \\ 7 Institute of Internal Combustion Engines and Thermodynamics, Graz University of Technology, \\ Inffeldgasse 19, A-8010 Graz, Austria; reifeltshammer@ivt.tugraz.at \\ * Correspondence: brigitte.wolkinger@uni-graz.at; Tel.: +43-316-380-8452
}

Received: 27 February 2018; Accepted: 23 April 2018; Published: 28 April 2018

\begin{abstract}
There is growing recognition that implementation of low-carbon policies in urban passenger transport has near-term health co-benefits through increased physical activity and improved air quality. Nevertheless, co-benefits and related cost reductions are often not taken into account in decision processes, likely because they are not easy to capture. In an interdisciplinary multi-model approach we address this gap, investigating the co-benefits resulting from increased physical activity and improved air quality due to climate mitigation policies for three urban areas. Additionally we take a (macro-)economic perspective, since that is the ultimate interest of policy-makers. Methodologically, we link a transport modelling tool, a transport emission model, an emission dispersion model, a health model and a macroeconomic Computable General Equilibrium (CGE) model to analyze three climate change mitigation scenarios. We show that higher levels of physical exercise and reduced exposure to pollutants due to mitigation measures substantially decrease morbidity and mortality. Expenditures are mainly born by the public sector but are mostly offset by the emerging co-benefits. Our macroeconomic results indicate a strong positive welfare effect, yet with slightly negative GDP and employment effects. We conclude that considering economic co-benefits of climate change mitigation policies in urban mobility can be put forward as a forceful argument for policy makers to take action.
\end{abstract}

Keywords: urban mobility; health co-benefits; physical activity; air pollution; climate change mitigation; interdisciplinary approach

\section{Introduction}

Previous studies have shown that implementation of low-carbon policies in the transport sector collaterally increases public health through increased physical activity and improved air quality, called health co-benefits, e.g., [1-6]. Yet, with respect to political decision processes, it seems as if 
these additional benefits (effectively implying policy cost reductions) are not taken into account and the narrowly defined implementation costs of mitigation measures are the prevailing criteria for decision makers.

Globally the transport sector accounts for $14 \%$ of the direct greenhouse gas (GHG) emissions ( $\mathrm{CO}_{2}$ equ in 2010) [7]. In Austria this sector is one of the largest emitters of GHG emissions (accounting for $29 \%$ of $\mathrm{CO}_{2}$ equ emissions in 2016) and the sector with the largest increase since 1990 (at 67\%) [8]. Nitrogen oxides and particulate matter (PM) impact health adversely, especially in urban areas with specific topographic and climatic constellations. Analyzing the conditions in Austria more closely, we find that in 2017 the number of days with $\mathrm{PM}_{10}$ exceeding the threshold level of $50 \mu \mathrm{g} / \mathrm{m}^{3}$ (daily average) were highest in Graz with 49 days, Linz with 25 and Vienna with 20 days [9]. Thus, for modelling health co-benefits of climate change strategies we focus on urban transport for these three largest Austrian cities. Furthermore, the mitigation potential of switching from motorized individual transport to public transport, bicycling or walking is large in urban areas due to available infrastructure and short distances between key locations of everyday life.

Recent studies have investigated the impacts of specific climate change strategies in urban transport and model the corresponding health effects (for an overview see [10-12]). The reviews show that most of the studies focus on active transport (biking and walking) [13,14], only some include low emission vehicles [15] and few include the use of public transport [2-4,16]. The health effects analyzed refer to changes in physical activity and air pollution; traffic injuries were less often evaluated. In this analysis, we evaluate co-benefits of increased physical activity and improved air quality by applying an interdisciplinary multi-model approach linking a transport modelling tool, a transport emission model, an emission dispersion model for air pollution impacts and a health model. We build on previous work $[6,15]$ that follows a typical procedure from baseline, impact assessment, valuation and sensitivity analysis [17].

Xia et al. [12] address a shortcoming of recent studies that economic valuation of benefits is still at an early stage, focusing only on a specific transport mode (e.g., HEAT Tool of the WHO for cycling [18]) or a specific cost factor like fuel savings (e.g., [14]). A macroeconomic approach considering implementation costs and health benefits of transport policies has only been applied for selected measures and not for the overall urban passenger transport system (e.g., [19]). In a similar vein, Koegh-Brown et al. [20] and Jensen et al. [21] model the implementation of a road pricing tax in order to achieve specific emission reduction targets and technological mitigation in separate scenarios. To the authors' best knowledge, a comprehensive and detailed macroeconomic assessment of climate change policies as it is presented here, has not been carried out until now. The role of public investments especially has thus far been neglected, but is included here.

We further enhance recent studies in different ways: first, we investigate health impacts for holistic passenger transport scenarios including domestic and commuter transport and considering changes in infrastructures, regulations, pricing and technologies. Three different scenarios are formulated and modelled for this purpose: the 'Green Mobility' scenario is based on the urban parliaments' targets for modal share of trips, the 'Green Exercise' scenario simulates a change in mobility behavior beyond the politically-accepted urban targets for the modal share and the 'Zero Emission' scenario corresponds to the Green Exercise scenario with all motorized trips conducted with electric energy.

Second, we provide an economic assessment of the implementation (investment and operating costs) of all policies (within the three scenarios) and of corresponding health effects, which both are implemented in a macroeconomic Computable General Equilibrium (CGE) model, calculating impacts on GDP, employment, welfare, relative prices and tax revenues.

Third, to be policy relevant, we start from the climate targets the urban parliaments have set for the modal share in 2020/2025 for urban mobility, i.e., current politically accepted plans, thereby addressing the critique by Xia et al. [12] that recent studies do not base their scenarios on local conditions and future plans of local authorities. 
Our results help policy makers to base their decisions not only on public and private investment and operating costs but include information on reduced public and private health costs and reduced productivity losses due to changes in morbidity and mortality and macroeconomic effects. This could convince policy makers to take decisions necessary to fulfill their GHG emission reduction targets.

\section{Methods}

For modelling the co-benefits for three types of scenarios in three Austrian cities, an interdisciplinary approach combining different model types has been applied. In general, we choose a comparative static approach. This means that the effects of any policy intervention on the transport system are compared to a case without such an intervention (ceteris paribus). We choose the year 2010 as a point of reference ("baseline") and calculate changes in transport performance and mileage, greenhouse gas emissions and air pollutants relative to the baseline. Put differently, we assume that the policy intervention has already been achieved in 2010 and compare this hypothetical state to the baseline. Starting with the modal share targets of the local parliaments for the three cities, the Transport Modelling Tool (1, cf. Figure 1) models changes in transport performance and mileage per transport mode and corresponding changes in energy use and $\mathrm{CO}_{2}$ equ emissions. This output serves as an input for the transport Network Emission Model (NEMO) (2a), which calculates road transport emissions (pollutants) by applying a top-down approach for assigning transport parameters to the traffic grid. This output is then used in a highly resolved Lagrangian Dispersion Model (2b) to model changes in emissions and concentration levels of pollutants for different health-related pollutants while using meteorological data (e.g., wind) and detailed fleet parameters (cf. Figure 1).

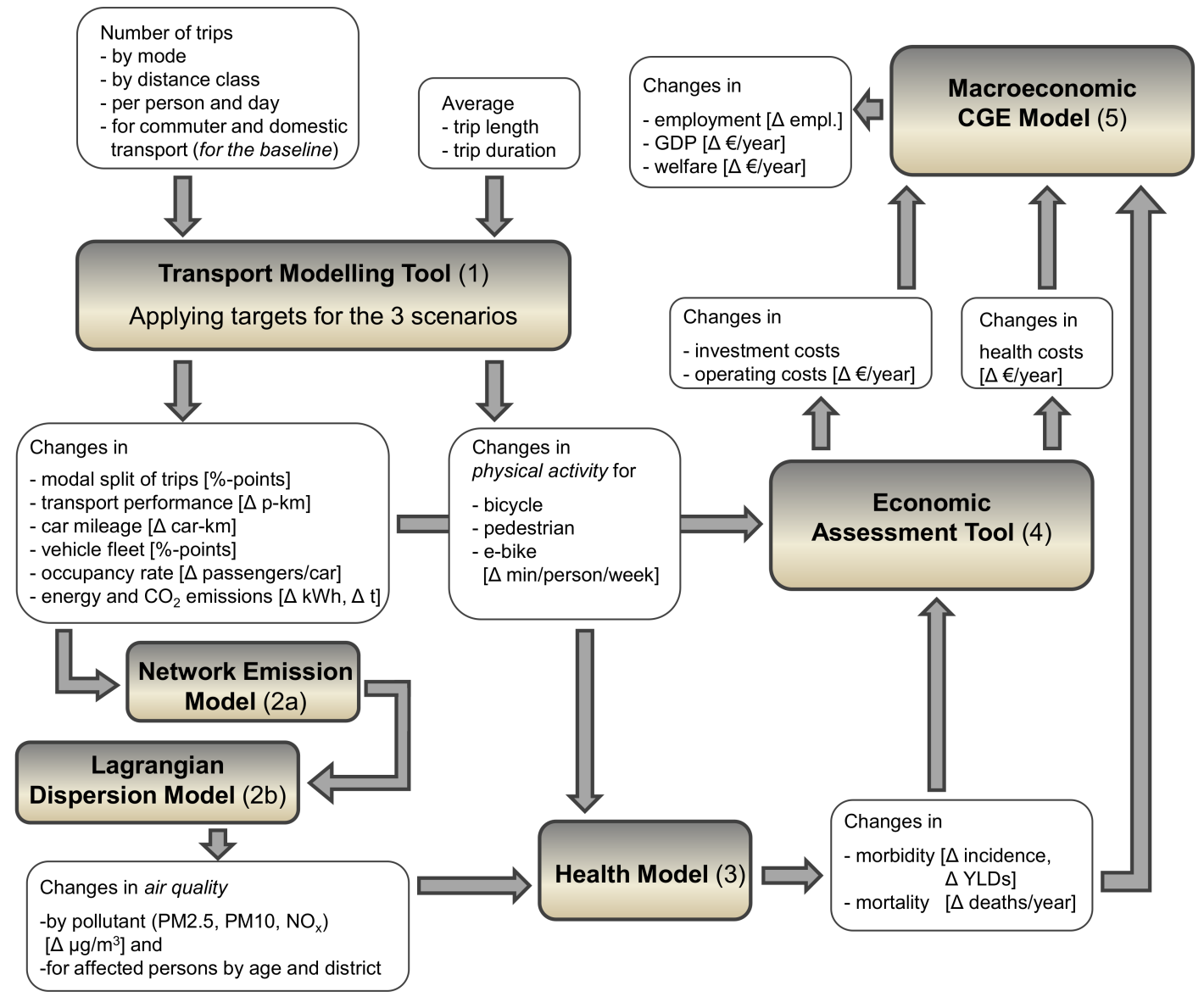

Figure 1. Interdisciplinary multi-model approach for calculating climate change effects and health co-benefits. 
Matching these data with data on population distribution yields the number of persons per district that are exposed to these changes in air quality. A second output of the Transport Modelling Tool refers to increased physical activity due to changes in modal share of trips (additional trips by bike, e-bike or foot), both affecting health. Based on changes of exposure of persons to emissions, relative risks obtained from literature (meta study) and changes in physical activity, the Health Model (3) calculates changes in morbidity and mortality for different diseases (i.e., cardiovascular diseases, lung cancer, respiratory diseases and myocardial infarction). Thus two input arrows from two different models enter into the Health Model as can be seen in Figure 1. This information is used for the Economic Assessment Tool (4) to calculate changes in private and public health costs as well as investment and operating costs for corresponding mitigation policies and in the macroeconomic CGE model (5). Finally, this CGE model calculates changes in employment, GDP and welfare using data of changed investment and operating costs and interrelated sectors as well as changes in health costs.

\subsection{Mobility Scenarios}

We develop three scenarios for changes in urban passenger transport, based on the transport action plans of the local governments of Graz, Linz and Vienna, which define targets for the modal share of trips for domestic and commuter transport [22-25] and partly corresponding policy strategies. Additionally, the action plans supply target levels for the occupation rate of car transport.

In the first scenario, 'Green Mobility' (GM), we assume that the politically-determined targets for the modal share of trips for the years 2020/2025 are almost achieved. Since we follow a comparative static approach, future changes in population and transport demand are not considered. The relevant policy strategies of the action plans comprise the improvement of pedestrian and bicycle infrastructure and service (environmental/pedestrian zones, restricted access for cars in the inner city), improvement of public transport and service as well as parking regulations.

In the second scenario 'Green Exercise' (GE) we assume a change in mobility behavior beyond the policy targets. This can be achieved by additional measures to promote active mobility (pedestrian and bike) and an expansion of access restrictions for cars in city centers combined with an expansion of public transport supply. In this scenario, domestic transport by cars is drastically reduced and commuter transport requires introduction of further incentives, such as price reductions for public transport.

For example, the share of car trips (domestic and commuters) in Vienna is reduced from $40 \%$ to $28 \%$ in the Green Mobility scenario and to $18 \%$ in the Green Exercise scenario. In turn the share of bike trips increases from $4 \%$ to $9 \%$ in 2010 and 14\%, respectively compared to the baseline (see Figure 2).

The focus of the third scenario 'Zero Emissions' (ZE) is long term and can be seen as a contribution towards achieving the $2{ }^{\circ} \mathrm{C}$ target that requires a substantial reduction of GHG emissions to near zero as mentioned in the IPCC's "Summary for policymakers" [26]. To meet this requirement, we assume the same modal shares as in the Green Exercise scenario but replace the remaining vehicleor passenger-kilometers, driven by conventional combustion engines, with electric cars and electric public transport.

The left-hand side panels of Figure 2 show the changes in the modal share of trips (share of trips in \%) for each city, for the baseline, Green Mobility (GM) and Green Exercise (GE) scenarios, the latter of which corresponds to the Zero Emission (ZE) scenario in terms of changes in transport performance (for both domestic and commuter transport). On the right-hand side, the modal share of transport performance is displayed (passenger-km). 


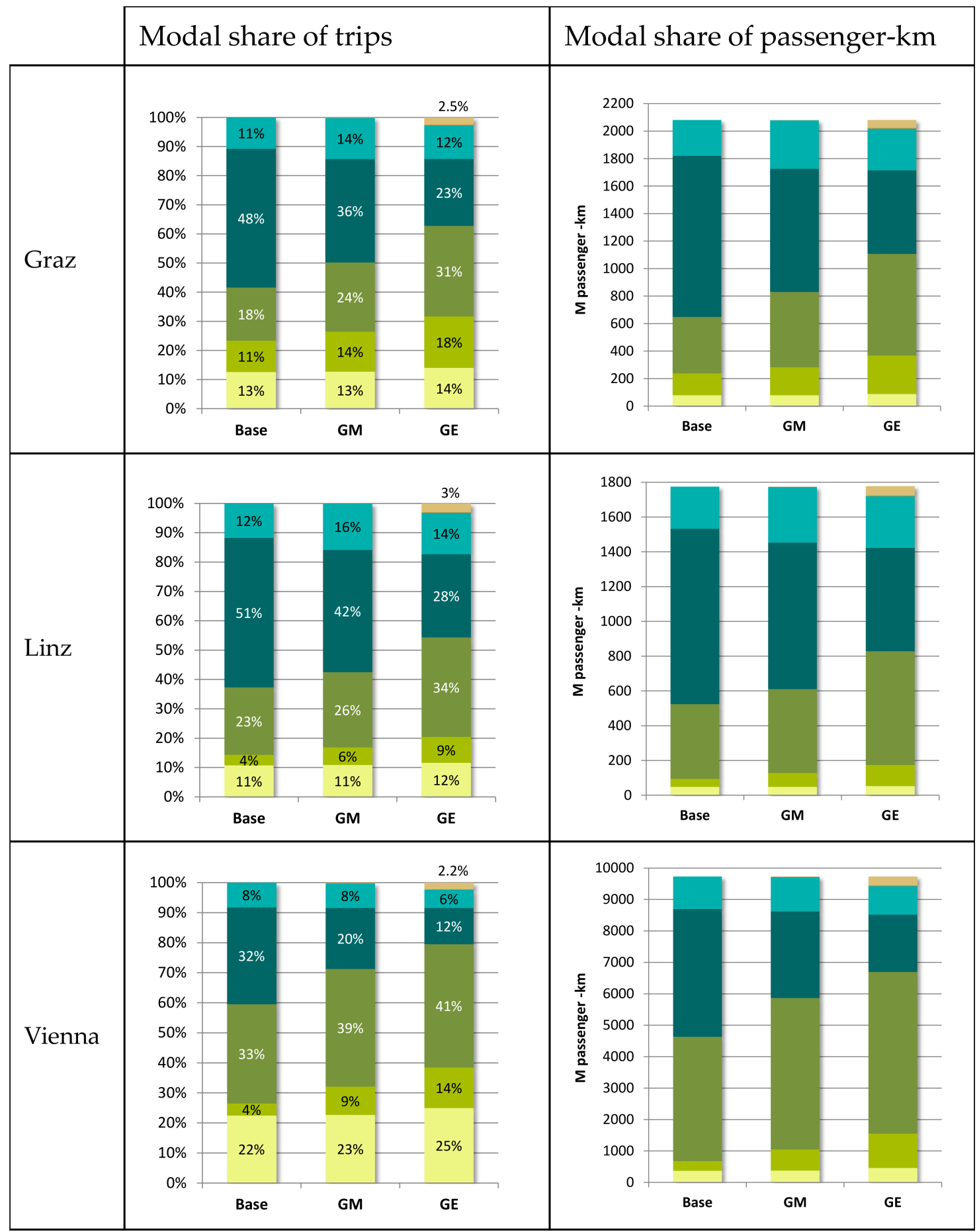

(a)

(b)

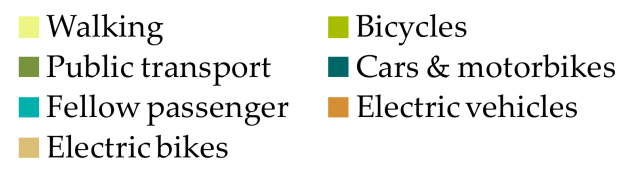

Figure 2. Modal share of trips [\%] (a) and transport performance (passenger-km) (b) for the three cities for the Baseline (Base), Green Mobility (GM) and Green Exercise (GE) Scenario. 


\subsection{Modelling Changes in Transportation, Physical Activity and Air Pollution}

Applying the Transport Modelling Tool (1), we derive changes in transport performance and mileage by scenario. The underlying data for this tool is based on local and regional transport surveys for working days and is comprised of the following baseline parameters for each city:

- Number of trips by category of trip length and mode (\#)

- Modal Share (\%)

- Number of trips per person and day $(\# / d / p)$

- $\quad$ Average trip length by transport mode $(\mathrm{km})$

- $\quad$ Average trip duration by transport mode (h)

These input data are entered into the Transport Modelling Tool (1) as shown at the top left in Figure 1. Traffic for weekends and commuter transport are based on the commuter statistics and regional transport surveys $[23,27]$. The tool is used to reach the overall modal share targets of the scenarios by shifting trips from one (motorized individual transport) to other groups (public transport, bicycle or pedestrian) within a certain distance category. Table 1 illustrates for Vienna for the GM scenario that $65 \%$ of all very short car trips (up to $1 \mathrm{~km}$ ) are shifted to other modes of transport, $8 \%$ thereof to pedestrian, $83 \%$ to bicycle, $7 \%$ to public transport and $1 \%$ to electric car and electric bike (pedelec) trips each. For each trip length category, the values are calibrated to meet the overall target shares of number of trips by mode as defined in the scenarios (Figure 2). Additionally, increased vehicle occupation rates for domestic and commuter transport (determined by local parliaments) are applied which further reduce overall absolute mileage.

Table 1. Example of shifting car trips (conventional drive) in Vienna for the scenario 'Green Mobility' to other modes of transport by different trip lengths.

\begin{tabular}{ccccccc}
\hline & Shifted Trips [\%] & Pedestrian & Bike & Public Transport & E-Car & E-Bike \\
\hline Domestic Transport & & & & & & \\
$0.01-0.99 \mathrm{~km}$ & 65 & $8 \%$ & $83 \%$ & $7 \%$ & $1 \%$ & $1 \%$ \\
$1.00-1.99 \mathrm{~km}$ & 50 & $5 \%$ & $85 \%$ & $8 \%$ & $1 \%$ & $1 \%$ \\
$2.00-2.99 \mathrm{~km}$ & 45 & $0 \%$ & $75 \%$ & $23 \%$ & $1 \%$ & $1 \%$ \\
$3.00-4.99 \mathrm{~km}$ & 35 & $0 \%$ & $55 \%$ & $43 \%$ & $1 \%$ & $1 \%$ \\
$5.00-9.99 \mathrm{~km}$ & 25 & $0 \%$ & $45 \%$ & $53 \%$ & $1 \%$ & $1 \%$ \\
Commuter Transport & & & & & & \\
$10.00-14.99 \mathrm{~km}$ & 20 & & & $93 \%$ & $1 \%$ & $1 \%$ \\
$>=15 \mathrm{~km}$ & 20 & & & & & 0 \\
\hline
\end{tabular}

The resulting changes in transport performance and mileage by transport mode as specified by the Transport Modelling Tool (1) enter into the transport Network Emission Model (NEMO) [28] (2a in Figure 1) which calculates road transport emissions (exhaust and non-exhaust) using detailed data on fleet composition (category, fuel types, emission classes etc.) and on road network (section lengths, gradients). These calculated road transport emissions, combined with meteorological data, comprise the input for the Lagrangian Dispersion Model GRAL [29], which is used to model concentration levels of pollutants for each scenario [30] (2b in Figure 1). Different diurnal and seasonal cycles are used to consider variability of pollutant sources. Changes in the annual mean of specific pollutants are calculated and matched with population data on the district level to determine the number of people affected by a specific change in exposure to specific pollutants. Figure 3 illustrates spatially-explicit modelled concentration levels for the city of Vienna at high resolution $(10 \mathrm{~m} \times 10 \mathrm{~m})$. Air pollution (annual mean for $\mathrm{PM}_{2.5}$ concentration) is exemplified by different colors for different concentration levels of pollutants for the baseline case and the three scenarios. Detailed concentration level maps for all cities and considered pollutants are given in Figures S3-S5 in the Supplementary Material.

In addition, we estimated health co-benefits from changes in the physical activity of pedestrians, bicyclists and e-bike users. These health effects are usually presented in relation to the weekly number 
of minutes people do additional exercise. In determining such effects we therefore need to derive both the number of people with increased activity and their extra minutes in active motion, both from our Transport Modelling Tool. By assuming average velocities for the different active modes we can convert the extra mileage of walking and biking into extra minutes. For example, for the Green Exercise scenario in Vienna there are 250,000 people using a bike for their trips instead of a car, yielding an additional 214 minutes of biking per week. Detailed results for all cities are given in Section 3.1.

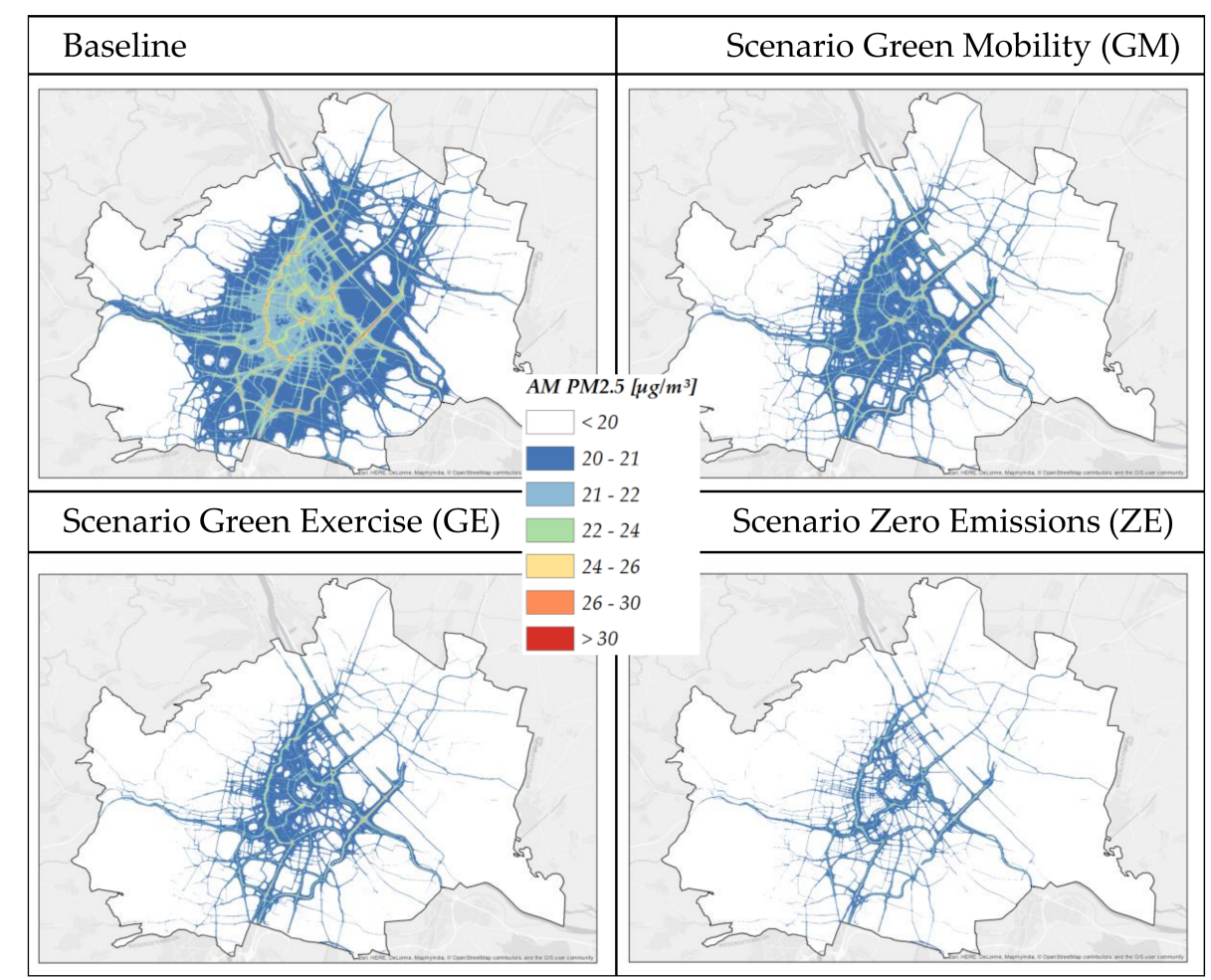

Figure 3. Annual mean concentrations of $\mathrm{PM}_{2.5}\left(\mu \mathrm{g} / \mathrm{m}^{3}\right)$ for Vienna (baseline and scenarios).

\subsection{Modelling Health Effects from Changes in Modal Shift}

\subsubsection{Physical Activity}

Based on changes in physical activity ( $\Delta \mathrm{min} /$ person/week) (see results of the Transport Modelling Tool, (1) in Figure 1) we can estimate the related changes in mortality (by the Health Model, 3). In the case of physical activity we do not need to calculate all three scenarios, since the scenario Zero Emissions (ZE) only replaces the combustion-engine-driven mobility in the Green Exercise (GE) scenario by electric vehicles, which does not alter the level of physical activity. The health impacts of increased physical activity are quantified by modelling the relationship between these factors and mortality, based on existing meta-analytical estimates. The functional relationship between Metabolic Equivalent of Task (MET) hours per week and the relative risk for all-cause mortality was estimated based on available meta-analyses [31-34] (MET is an equivalent of physical activity. It is in units of basic metabolic rate [35]). Accordingly, a more physically active person's relative risk of death (RR; defined as the ratio between the risk of an exposed person to the risk of another person not or less exposed) is lower than that of another person with lower activity levels. RR and Hazard Risks (HR) are similar indicators, albeit with small conceptual differences related to time. Hazard ratio provides instantaneous risk at a particular time and relative risk pertains to cumulative risk over a span of time [36]. Based on individual HR we calculated HR for atraumatic mortality for the affected group for each city, considering the actual changes in activity levels introduced by the scenarios. The atraumatic mortality includes all mortality causes except injuries (code: A00-R99; World Health Organisation International Classification of Diseases, ICD-10 [37]). 
With the HR as shown in Table 2, in combination with population [38] and cause of death statistics [39], we calculate the potential changes in mortality due to the discussed changes in urban mobility for 2010. For those persons engaged in active mobility in each scenario, the number of deaths was determined from cause of death statistics, in proportion to the size of the group, to calculate the mortality rate before the additional exercise. Applying the HR reduces mortality accordingly, as the design of the study implies that the group would have already been engaged in such additional active mobility by the year 2010, with its corresponding health benefits e.g., reduced mortality risk. Data on Years of Life Lost (YLL), YLL is an indicator for lost years due to premature mortality, were obtained from the Institute for Health Metrics and Evaluation database [40], but only for Austria as a whole. This necessitated calculation of a YLL per death ratio, which was applied for the three target cities to calculate the amount of YLL per city.

Table 2. Hazard risks (HR) for the more active group in each city and scenario according to their changes in activity levels for atraumatic mortality.

\begin{tabular}{ccccccc}
\hline City & \multicolumn{2}{c}{ Graz } & \multicolumn{2}{c}{ Linz } & \multicolumn{2}{c}{ Vienna } \\
\hline Scenario & GM & GE & GM & GE & GM & GE \\
\hline Hazard Risk (HR) & 0.773 & 0.770 & 0.765 & 0.767 & 0.772 & 0.769 \\
\hline
\end{tabular}

\subsubsection{Air pollution}

Based on the reduced exposure of the general public to air pollution, we calculate reduced morbidity and mortality figures for each city and scenario (in this case, the ZE scenario reduces health-relevant pollutants beyond the reductions of the GE scenario). We can perform this calculation similarly for all three most commonly used health-relevant air pollutants $\left(\mathrm{PM}_{10}, \mathrm{PM}_{2.5}\right.$ and $\left.\mathrm{NO}_{2}\right)$ but it bears consideration that the reduced mortality for each of the pollutants cannot simply be summed up, as health effects are overlapping, meaning that a reduced case of death due to reduced $\mathrm{NO}_{2}$ cannot be saved a second time via reduced $\mathrm{PM}_{10}$. Since these pollutants affect the same group and usually occur in combination, we can therefore only consider the strongest result for further calculations.

The health impacts of a reduction in air pollution were quantified by modelling the relationship between these factors and mortality, based on meta-analytical estimates displayed in Table 3 . For coronary events and lung cancer, Hazard Risk (HR) indicators are applied. Relative risk values for the diseases have been obtained by carrying out a systematic review including meta-analysis of large, international epidemiological studies [41-46].

Table 3. Relative Risks (RR) and Hazard Risks (HR) (95\% CI) for different health endpoints per $10 \mu \mathrm{g} / \mathrm{m}^{3}$ increase of $\mathrm{NO}_{2}, \mathrm{PM}_{2.5}$ and $\mathrm{PM}_{10}$.

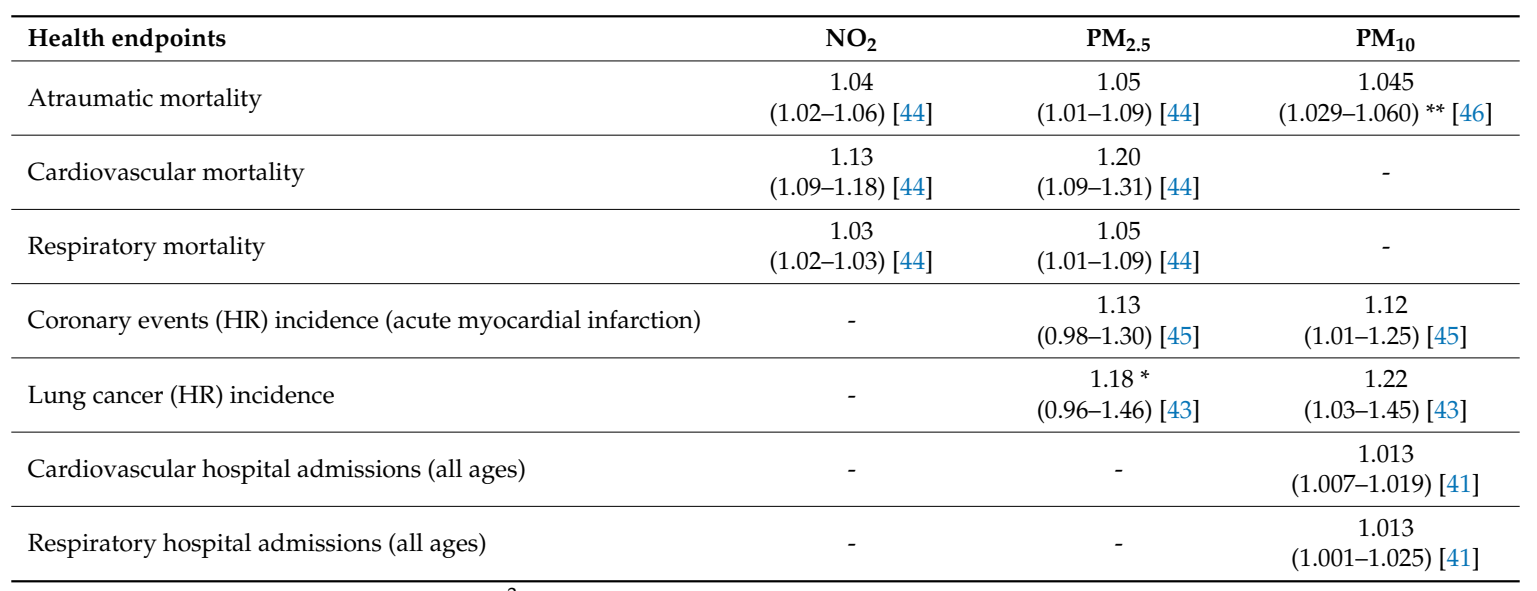

${ }^{*}$ HR per $5 \mu \mathrm{g} / \mathrm{m}^{3}$, ${ }^{* *}$ RR from Vienneau et al. [46] based on Hoek et al. [42]. 
Based on the exposure of persons to the included pollutants $\left(\mathrm{NO}_{2}, \mathrm{PM}_{2.5}\right.$ and $\left.\mathrm{PM}_{10}\right)$ and the RR and HR, new values for "Atraumatic mortality (A00-R99)", "Cardio-vascular mortality (I00-I99)", "Respiratory mortality (J00-J99)", "Myocardial infarction (I21-I22)" and "Lung cancer (C33-C34)" (according to the ICD-10 classification) were calculated. Data from the National Causes of Death Statistics [39], the Austrian Cancer Registry [47] and the Austrian Hospital Admission Statistics [48] is used. The myocardial infarction incidence is estimated by combining data from the National Causes of Death Statistics [39] and from the Austrian Hospital Admission Statistics [48]. Data on Years of Life Lost (YLL) and Years lived with Disability (YLD) were obtained from the Institute for Health Metrics and Evaluation database [40] for all mentioned outcomes.

Since the cities' entire population is affected, we obtained the relevant mortality and incidence data from statistics mentioned above for the baseline. The resulting actual risks can be further altered by applying the RR as displayed in Table 3 to obtain a new number for the different risks and finally, to show the reduced death cases or incidences. For a more detailed explanation of the Health Model see chapter $\mathrm{S6}$ in the Supplementary Material.

\subsection{Economic Assessment}

Based on the results of the Transport Modelling Tool (1), the Lagrangian Dispersion Model (2b) and the Health Model (3), changes in costs and benefits (i.e., saved costs) relative to the baseline were assessed by the Economic Assessment Tool (4).

\subsubsection{Investment Costs and Operating Costs}

As we are interested in a comprehensive evaluation of health co-benefits of climate change mitigation measures, we also have to account for the associated costs of these measures. The costs are either one time investment costs (for the implementation of e.g., charging infrastructure) or recurring operating costs. In addition we account for who is bearing the different costs; either the public sector or private households.

In the first step, we calculate all the investment and operating costs for the required mitigation measures. Implementation costs and corresponding operating costs are calculated for the investments throughout the total planning period by OENACE sectors [49] and investor (private/public) and broken down on an annual basis by applying typical amortization rates. OENACE is the Austrian version of the Statistical Classification of Economic Activities in the European Community (called NACE). The NACE version used is revision 2. Additionally, changes in private expenditures (as a part of operating costs) due to a shift from motorized individual transport to pedestrian or bike are calculated based on the Austrian Household Budget Survey 2009/2010 [50]. Household expenditures are combined with data on transport performance by mode [51] in order to calculate cost factors per saved car-kilometer (see chapter S5 of the Supplementary Material for an exemplified calculation).

\subsubsection{Health Costs and Benefits}

For evaluating changes in health costs we apply the cost-of-illness approach, which distinguishes between direct and indirect cost components [52-54] and intangible costs. Direct costs refer to costs for medical procedures and services for treatment and care of a disease. They can further be divided into direct medical and direct non-medical costs (cf. Le et al. [55]). The former include medical treatment (in hospital or outside) and medicine while the latter include costs of transportation of patients and family members, costs of accommodation during visits etc. The latter costs are mainly borne by households privately and could not be appraised due to lack of data. Indirect costs refer to productivity losses due to morbidity and mortality. Intangible costs are controversial as they refer to costs from e.g., pain, anxiety or the hypothetical costs for the value of life lost. While former studies value premature death by means of the value of statistical life (VSL) there is growing recognition that it is more meaningful to value changes in life expectancy and to apply the value of life year (VOLY), especially for air pollution, which shortens everyone's life to some extent [56,57]. Desaigues et al. [58] 
conducted a large contingent valuation study for European countries and recommend a value of $40,000 €$ per life year lost due to premature death (Years of Life Lost, YLL) and disease (Years Lived with Disability, YLD) expressing the willingness to pay for extending one's life expectancy. We multiply a VOLY of 43,000 $€$ which is adjusted by the Austrian CPI (consumer price index) value of 7.9\% [59] for the base year 2010 by changes in YLL and YLD due to increased physical activity and improved air quality. This value is a conservative one as other European studies use higher values e.g., 50,000€ from ExternE [57] or 60,000 $€$ from the HEIMTSA study [60]. In a sensitivity analysis we calculate the economic effects for a higher VOLY and compare them to the VSL results (applying a value of $1,650,000 €[60]$ for changes in death cases).

As the list of cost components in relation to different diseases is long, in practice there are limits to what can be measured and valued due to lack of consistent data of the health care system. In the following we describe which cost components have been valued in the underlying study.

The calculations were based on the results of the Health Model (3) which models changes in morbidity for cardiovascular diseases, respiratory diseases, myocardial infarction, lung cancer and atraumatic mortality. Changes are expressed in incidence, deaths as well as corresponding YLD or YLL. These input data enter into the Economic Assessment Tool (4) as can be seen in Figure 1.

Calculations of changes in direct medical costs are based on the available data for acute stationary stays for 2010 [61]. Absolute numbers for YLD for the base year 2010 represent the years of life living with disability or the state of health within the population for this year. Thus we merge the costs for stationary stays (private and public) with the YLD for the year 2010. With the hence derived costs factor ( $€ / Y L D)$, decreases of YLD per disease produced by the Health Model are valued. As within the Health Model YLD changes can only be calculated for changed air quality, but not for changes in physical activity, effects of the latter are appraised by applying the results of Alt et al. [62]. These authors appraise the national costs of inactivity and the benefits for increased physical activity. They include direct and indirect health cost components and consider increased accidents due to increased activity which partly offset health benefits. Based on the number of active persons and the direct and indirect health costs for the base year derived from Alt et al. [62], a cost factor (of $€$ /active person) is calculated. This factor is multiplied with the changes in the amount of active persons due to a switch from car to pedestrian or bike (derived from the Transport Modelling Tool) in order to calculate changes due to increased physical activity. Expenditures on medicine are appraised from the literature, taking the lower bound of about 5\% due to lack of data for Austria (range between 5-35\% depending on the disease, cf. e.g., Brown et al. [63].

Changes in productivity of the labor force due to morbidity are calculated by valuing the reduction of sick leaves with the gross median income per working day. This is done by merging incidence numbers with the average number of days with sick leaves per disease and year for the baseline (Table 4) [64].

Table 4. Sick leaves for diseases triggered by air pollution and physical activity.

\begin{tabular}{cc}
\hline Disease & Mean Number of Days of Sick Leave per Year \\
\hline Myocardial infarction & 37.5 \\
Lung cancer & 75.0 \\
\hline & \\
\hline
\end{tabular}

The gross median income per employee for 2010 was obtained from Statistics Austria (2016) and was divided by 244 (working days) to yield the cost per working day of about $100 €$. Cost changes due to reduced mortality per disease category were calculated by applying a human capital approach [65]. Productivity costs due to mortality are thus measured by gross wages lost for the period from the age when death occurs to the age of retirement.

Changes in mortality in the scenarios are only given in absolute terms and not divided by age group. In order to obtain the productive years until the age of retirement and monetize them with 
the average gross median income, we transfer the current distribution of deaths across age groups for Austria from the Global Burden of Disease Study 2015 [40] to the changes in mortality in the scenarios. Previously lost productive years due to morbidity that can be regained in the scenarios lead to cost savings. In the underlying study, benefits from reduced productivity losses are considered.

\subsection{The Macroeconomic Model}

In a final step we feed the derived costs and benefits into a macroeconomic national Computable General Equilibrium (CGE) model, which is described in Bachner [66]. The model is based on the input-output table of Statistics Austria (2011) and describes the Austrian economy as annual monetary flows across producers, consumers and the government. These flows are in equilibrium in which all markets are cleared simultaneously. Austria is modelled as a small open economy, therefore part of the domestic production is exported. Imports and domestic goods are only partially substitutable [67]. A detailed description of the model type is provided for example by [68].

The model comprises two representative end users (a representative private household and a government) as well as 48 production sectors (see Table A1 in the Appendix A). The private household is endowed with the production factors labor and capital, which generate income when supplied to the market. This factor income (wages and capital income) is used by the household to maximize utility, subject to a nested constant elasticity of substitution (CES) function. Production sectors use the supplied production factors and combine them together with other intermediate inputs (i.e., output from other sectors) to produce goods and services, also subject to a nested CES function. The government yields its income from taxation and spends it for public consumption, such as transport infrastructure, schools or the health system.

As all sectors and end users are interconnected (due to the underlying input-output structure), localized interventions in one part of the model (e.g., the mobility sector, or in the household's or government's final demand structure) have indirect impacts on all other sectors and end users, leading in turn to overall macroeconomic effects, which are measured as changes in GDP, employment or welfare (relative to the baseline).

The procedure to determine macroeconomic effects is the following: the baseline equilibrium (year 2011) in markets is exogenously shocked, e.g., by changes in transport-related expenditures by households, leading to changes in demanded quantities and consequently to changes in relative prices until a new equilibrium emerges (in which all markets are cleared again). By comparing model variables between the two equilibria (i.e., prior and after the shock), we capture the long-term effects for the whole economy but also for different sectors and end users. Again, note that we follow a comparative static approach.

In the CGE model we account for the direct expenditures necessary for implementation of the policies (as described in Section 2.4.1) as well as for the health benefits (i.e., cost savings) emerging from these policies (as described in Section 2.4.2).

Regarding the direct costs for policy implementation we model (i) changes in private operating costs due to changes in transport behavior (e.g., less demand for fossil fuels and repair services but more demand for electricity), (ii) changes in private investments (e.g., more investment in electric cars and bike, but less in conventional cars), (iii) changes in public operating costs (e.g., higher costs for public transport) and (iv) changes in public investments (e.g., additional costs for civil engineering for railroads).

Health cost savings that have been assessed work through two main channels in the CGE model: First, the changes in sick leaves are translated into changes of labor productivity and second, the changes in health expenditures for the government are reduced (leaving more budgets available for other public good provision). The overall macroeconomic effects are displayed as changes in GDP, welfare, employment rate, relative prices and tax revenues. 


\section{Results}

\subsection{Transport and Environment}

If measures are implemented leading to changes in the modal share of trips in line with targets by the local governments, substantial changes in vehicle mileage conducted by car can be expected. In the Green Exercise or Zero Emission scenario (which is equal with respect to changes in transport performance) this leads to a reduction in vehicle mileage of up to 55\% relative to the baseline for Vienna (see Table 5 last column). Additionally bus kilometers relative to the baseline will increase up to $35 \%$. For Graz this increase is highest as bus is the predominant transport mode at present, while in Vienna and Linz, electric transport modes are used that can be enhanced.

Table 5. Changes in vehicle mileage for the scenarios Green Mobility and Green Exercise (correspondingly Zero Emission scenario) relative to the baseline 2010.

\begin{tabular}{lcc}
\hline Changes in mileage by city & Green Mobility & $\begin{array}{c}\text { Green Exercise } \\
\text { (Zero Emission) }\end{array}$ \\
\hline Changes in car-km relative to the baseline (million km and \%) & $-1306(-32 \%)$ & $-2241(-55 \%)$ \\
Vienna & $-276(-24 \%)$ & $-564(-48 \%)$ \\
Graz & $-166(-16 \%)$ & $-416(-41 \%)$ \\
Linz & & $17 \%$ \\
Changes in bus-km relative to the baseline (\%) & $17.8 \%$ & $34.6 \%$ \\
Vienna & $15.9 \%$ & $21.6 \%$ \\
Graz & $4.7 \%$ & \\
Linz & & \\
\hline
\end{tabular}

Correspondingly, these changes lead to substantial reductions in energy use and GHG emissions. Summarizing the climate mitigation impact of all three cities, the targeted trip changes lead to a reduction of about 290,000 $\mathrm{t} \mathrm{CO}_{2}$ equ in the Green Mobility scenario and of almost 530,000 $\mathrm{t} \mathrm{CO}_{2}$ equ in the Green Exercise scenario as displayed in Figure 4. For the Zero Emission scenario the switch from conventional engines to electric engines will lead to a reduction of $\mathrm{CO}_{2} \mathrm{equ}$ of $1,000,000 \mathrm{t}$ relative to the baseline (1,200,000 $\mathrm{t}$ in 2010, i.e., $12 \%$ of the Austrian emissions in the passenger transport sector). If electric power is produced in a carbon neutral manner, emissions are reduced to zero.

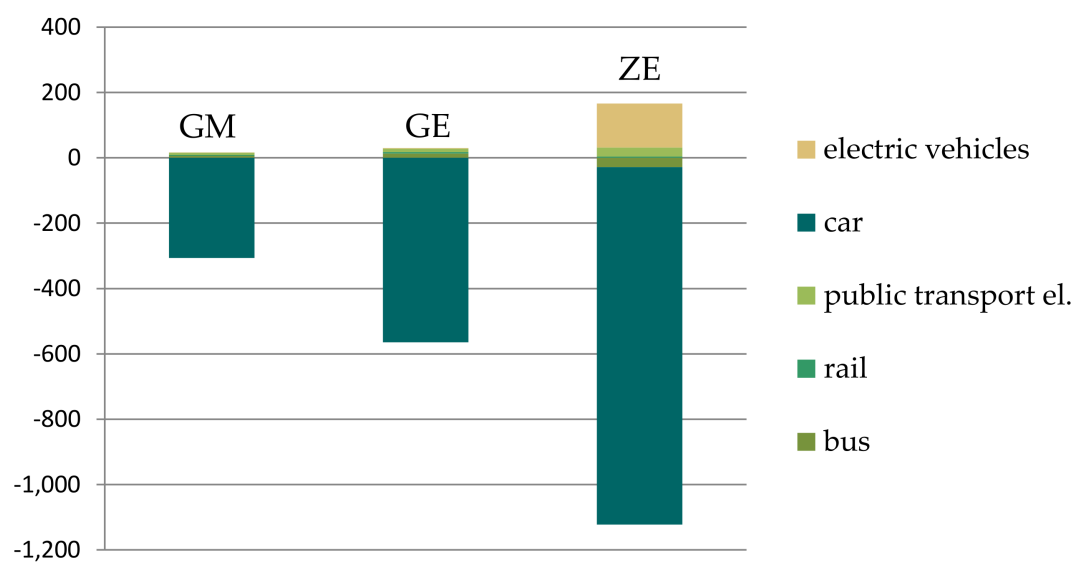

Figure 4. Changes in $\mathrm{CO}_{2}$ equivalent emissions (1000 $\mathrm{t}$ ) for the three scenarios (all urban areas) relative to the baseline.

Besides the effects on overall mileage and emissions of $\mathrm{CO}_{2} \mathrm{equ}$ and other pollutants, these changes translate to additional physical activity. Table 6 shows the number of people switching to healthier ways of transportation for each scenario and the additional minutes per person and week. These results enter into the Health Model (3) as displayed in Figure 1. 
Table 6. Additional physical activity due to increased walking and biking (number of persons, minutes per person and week).

\begin{tabular}{|c|c|c|c|c|c|c|}
\hline \multirow{2}{*}{ Scenario } & \multicolumn{2}{|c|}{ Pedestrian } & \multicolumn{2}{|c|}{ Biker } & \multicolumn{2}{|c|}{ E-Biker } \\
\hline & Persons & Minutes & Persons & Minutes & Persons & Minutes \\
\hline Graz GM & 675 & +167 & 18,599 & +178 & 734 & +173 \\
\hline Graz GE & 8666 & +217 & 37,673 & +206 & 3101 & +263 \\
\hline Linz GM & 588 & +187 & 10,872 & +237 & 416 & +187 \\
\hline Linz GE & 3954 & +227 & 20,398 & +233 & 1754 & +287 \\
\hline Vienna GM & 5014 & +212 & 153,939 & +180 & 4702 & +160 \\
\hline Vienna GE & 71,013 & +239 & 254,449 & +214 & 12,662 & +258 \\
\hline
\end{tabular}

\subsection{Health Effects}

For the Green Mobility scenario, health results due to increased physical activity and air quality show a prevention of 417 atraumatic deaths due to physical activity and between 3 and 135 cases due to improved air quality depending on the pollutant and the disease. For the Green Exercise and Zero Emission scenario with a higher amount of people using active mobility, 891 deaths are prevented for all cities. The changes due to air quality are higher for the Zero Emission scenario than for the Green Exercise scenario with 284 to 647 prevented death cases, respectively (Table 7).

Table 7. Changes in mortality due to increased physical activity and changes in air quality relative to the baseline for all cities (death cases).

\begin{tabular}{ccccc}
\hline Death Cases & $\begin{array}{c}\text { Cause } \\
\text { (activity, air quality) }\end{array}$ & Green Mobility & Green Exercise & Zero Emissions \\
\hline Atraumatic Mortality & Physical Activity & -417 & -891 & -891 \\
& $\mathrm{NO}_{2}$ & -88 & -185 & -421 \\
& $\mathrm{PM}_{2.5}$ & -48 & -58 & -65 \\
& $\mathrm{PM}_{10}$ & -41 & -70 & -91 \\
\hline Cardiovascular Diseases & $\mathrm{NO}_{2}$ & -135 & -284 & -647 \\
& $\mathrm{PM}_{2.5}$ & -91 & -110 & -123 \\
\hline Respiratory Diseases & $\mathrm{NO}_{2}$ & -4 & -8 & -18 \\
& $\mathrm{PM}_{2.5}$ & -3 & -3 & -4 \\
\hline
\end{tabular}

Reduced atraumatic mortality due to physical activity and cardiovascular disease mortality due to reduced $\mathrm{NO}_{2}$ exposure is displayed in relation to 100,000 inhabitants in Figure 5, summarized for all cities. Due to increased physical activity and air quality, decreases in mortality between 27 and 58 per 100,000 inhabitants (GM and GE scenario) can be expected. For the Zero Emission scenario this number is even higher with 76 less cases of death/100,000 inhabitants.

Table 8 gives a more detailed view on disease-specific mortality for the pollutants $\mathrm{NO}_{2}, \mathrm{PM}_{2.5}$ or $\mathrm{PM}_{10}$. Changes in YLD which are applied for calculating changes in health costs (Economic Assessment Tool, 4, in Figure 1) are only available for lung cancer and myocardial infarction and are displayed in brackets in corresponding rows.

A reduction of $\mathrm{NO}_{2}$ can save 138 to 665 lives (deaths due to cardio-vascular disease and respiratory disease). The effect of $\mathrm{PM}_{10}$ reduction can prevent 27 to 60 myocardial infarction (MI) incidence cases and would reduce the YLD by about 0.4 to 0.9 years. Furthermore, the number of avoided lung cancer cases by $\mathrm{PM}_{2.5}$ reductions ranges between 23 avoided cases for the GM scenario and 30 for the $\mathrm{ZE}$ scenario and would reduce the YLD by about 2.2 to 3.1 years. 


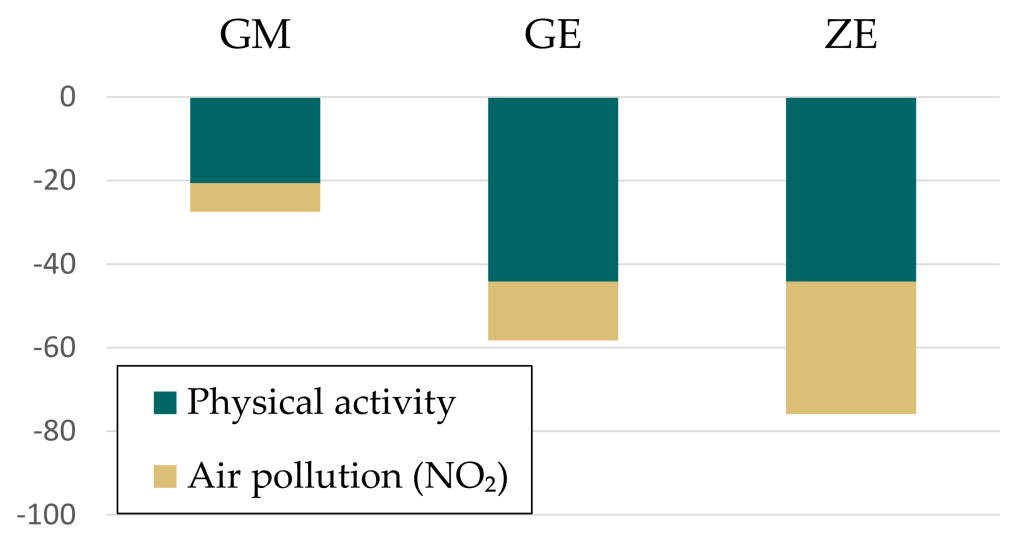

Figure 5. Changes in atraumatic mortality per 100,000 inhabitants due to increased physical activity and cardiovascular disease mortality changes due to $\mathrm{NO}_{2}$ decreases.

Table 8. Changes in death cases, incidence numbers, hospital admissions and YLD (displayed in brackets) for the three cities and scenarios due to changed air quality.

\begin{tabular}{cccccccccc}
\hline \multirow{2}{*}{ Changes in } & \multicolumn{3}{c}{ Graz } & \multicolumn{3}{c}{ Linz } & \multicolumn{3}{c}{ Vienna } \\
\cline { 2 - 10 } & GM & GE & ZE & GM & GE & ZE & GM & GE & ZE \\
\hline Cardiovascular mortality $\mathrm{NO}_{2}$ & -26 & -48 & -99 & -1 & -14 & -50 & -107 & -222 & -498 \\
\hline Respiratory mortality $\mathrm{NO}_{2}$ & -1 & -1 & -3 & 0 & -1 & -2 & -3 & -6 & -13 \\
\hline $\begin{array}{c}\text { Myocardial infarction } \\
\text { Incidence } \mathrm{PM}_{10}\end{array}$ & -4 & -0 & -10 & -3 & -6 & -7 & -20 & -34 & -43 \\
\hline $\begin{array}{c}\text { Lung cancer }(\mathrm{HR}) \\
\text { Incidence } \mathrm{PM}_{2.5}\end{array}$ & $\begin{array}{c}-2 \\
(-0.2)\end{array}$ & $\begin{array}{c}(-0.1) \\
-0.3)\end{array}$ & $(-0.1)$ & $(-0.02)$ & $(-0.05)$ & $(-0.08)$ & $(-0.3)$ & $(-0.5)$ & $(-0.7)$ \\
\hline $\begin{array}{c}\text { Cardiovascular hospital } \\
\text { admissions } \mathrm{PM}_{10}\end{array}$ & -8 & -14 & -17 & -3 & -7 & -12 & -34 & -57 & -72 \\
\hline $\begin{array}{c}\text { Respiratory hospital } \\
\text { admissions } \mathrm{PM}_{10}\end{array}$ & -5 & -8 & -10 & -2 & -4 & -7 & -18 & -31 & -39 \\
\hline
\end{tabular}

Figure 6 shows changes in Disability-Adjusted Life Years (DALYs) which are calculated as the sum of the YLL due to premature mortality in the population and the YLD for people living with the health condition or its consequences [69].

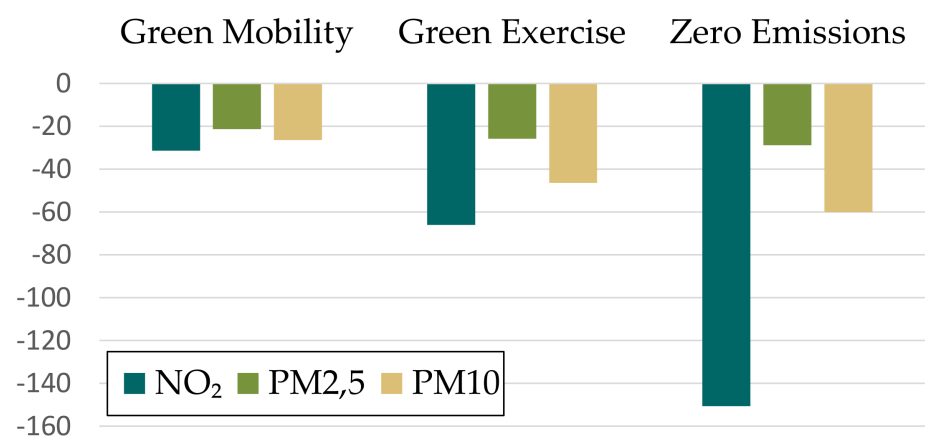

Figure 6. Changes in Disability-Adjusted Life Years (DALYs) per 100,000 inhabitants for the pollutants $\mathrm{NO}_{2}, \mathrm{PM}_{2.5}$ and $\mathrm{PM}_{10}$. 


\subsection{Economic Effects of Mitigation Measures and Co-Benefits}

\subsubsection{Changes in Implementation Costs, Operating Costs and Household Expenditures}

Figure 7 shows changes in expenditures for private households due to the shifts from car trips to cycling and walking trips as well as trips conducted by public transport. The savings primarily include operating costs of conventional cars. Considering the total timespan up to 2025, a gradual reduction of new car purchases is considered, leading to additional savings of fixed cost components. Private investment costs are higher for the ZE scenario compared to the other scenarios, as all conventional drives have been shifted to electric vehicles in this scenario and the purchase price for electric vehicles is much higher. Still, there is a net saving for the households in the ZE scenario since private operating costs are reduced to a higher degree.

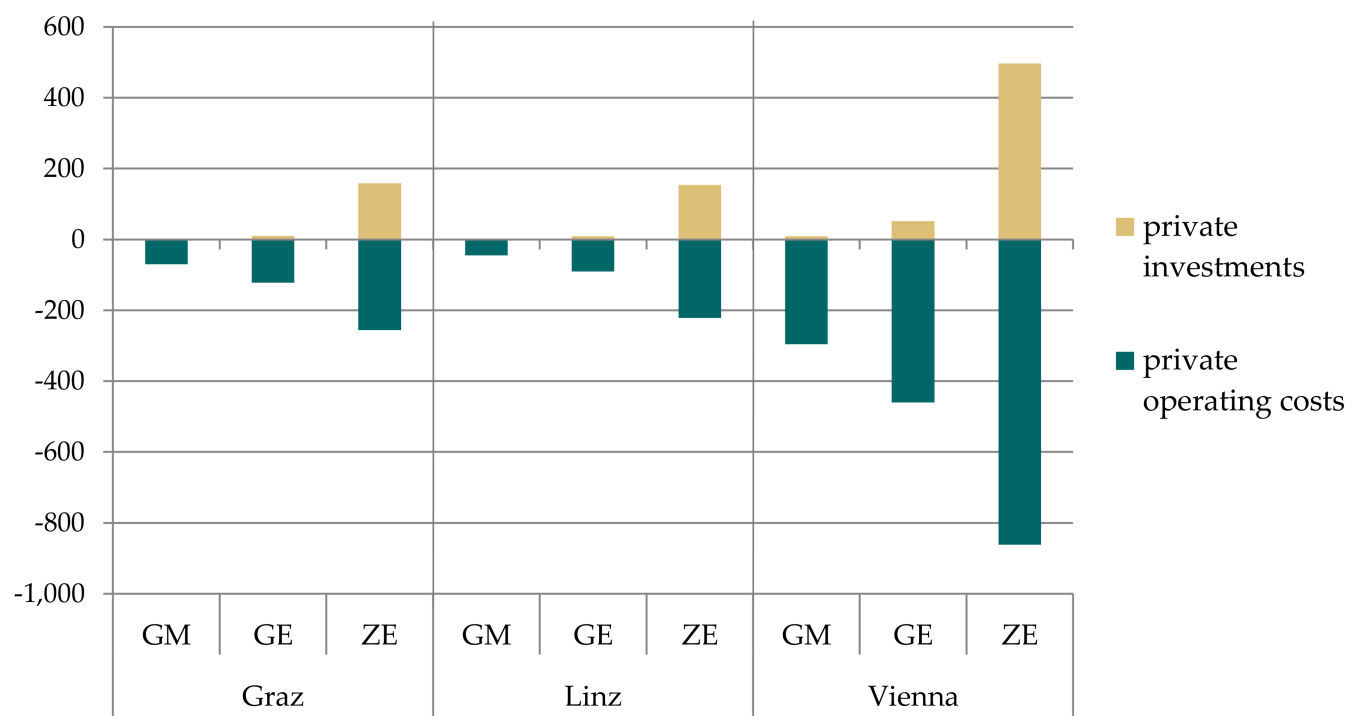

Figure 7. Changes in private investment and operating costs relative to the baseline for all three cities and scenarios (M€ p.a.).

For the public sector, additional net costs occur due to investments in public transport, pedestrian and bike lanes and the provision of charging infrastructure for e-mobility in public space (Figure 8).

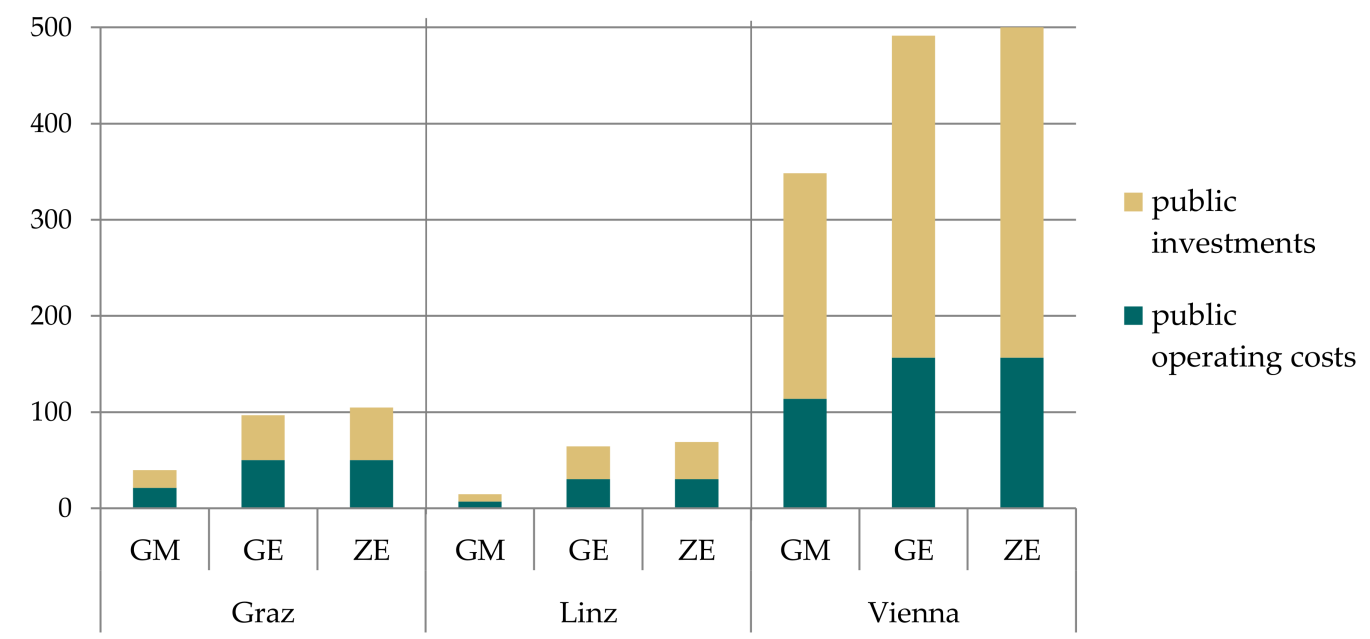

Figure 8. Changes in public investment and operating costs relative to the baseline for all three cities and scenarios (M€ p.a.). 
Figure 9 contrasts the additional costs with the savings for the different scenarios and cities due to implemented climate change mitigation measures. For the GM and GE scenario savings for private households exceed expenditures from households and the public sector for Graz and Linz. For Vienna costs are slightly higher than savings due to the very ambitious modal share targets and required extension of public transport, bike and pedestrian infrastructure. For the ZE scenario, expenditures slightly exceed savings in all three cities due to additional costs for switching from conventional drives to electric vehicles. Future cost degradation was not included in the calculation which could change the results.

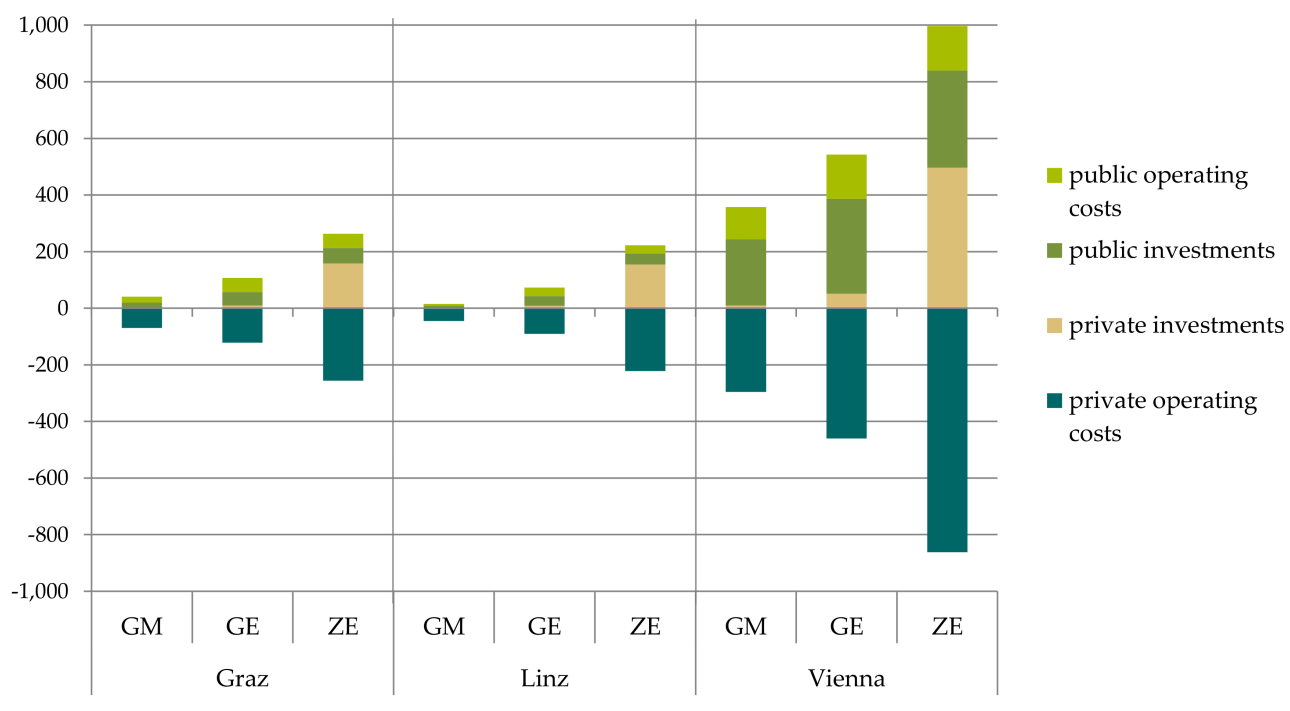

Figure 9. Summary of costs and benefits in private and public investment and operating costs relative to the baseline for all three cities and scenarios (M€ p.a.).

\subsubsection{Changes in Health Costs}

Table 9 summarizes changes in direct and indirect health costs due to changes in air quality and physical activity for the three Austrian cities and the three scenarios.

Table 9. Health and intangible costs relative to baseline due to changes in mortality and morbidity (all values per year).

\begin{tabular}{|c|c|c|c|}
\hline Direct and indirect health costs and intangible costs & Green Mobility & Green Exercise & Zero Emissions \\
\hline \multicolumn{4}{|l|}{ Changes due to improved air quality } \\
\hline \multicolumn{4}{|l|}{ Direct costs (in €1000) } \\
\hline Acute in-patient treatment including medicine & -2850 & -3940 & -4680 \\
\hline \multicolumn{4}{|l|}{ Indirect costs } \\
\hline Morbidity (work absence in days) & -2740 & -3730 & -4350 \\
\hline Morbidity (in $1000 €$ ) & -280 & -380 & -440 \\
\hline Mortality (number of persons) & -135 & -284 & -647 \\
\hline Mortality (in $1000 €$ ) & -4290 & -4400 & -4600 \\
\hline \multicolumn{4}{|l|}{ Changes due to increased physical activity } \\
\hline Direct and indirect costs (in $1000 €)$ & -4350 & -9200 & -9200 \\
\hline Mortality (number of persons) & -417 & -891 & -891 \\
\hline $\begin{array}{l}\text { Total changes of direct and indirect costs (air quality } \\
\text { and increased physical activity) (in } 1000 € \text { ) }\end{array}$ & $-11,770$ & $-17,920$ & $-18,920$ \\
\hline \multicolumn{4}{|l|}{$\begin{array}{l}\text { Changes in intangible costs due to improved air quality } \\
\text { and increased physical activity (in } 1000 € \text { ) }\end{array}$} \\
\hline $\operatorname{VOLY}(€ 43,000)$ & $-352,700$ & $-715,600$ & $-738,500$ \\
\hline VOLY $(€ 60,000)$ & $-490,400$ & $-995,000$ & $-1,026,800$ \\
\hline VSL $(€ 1,650,000)$ & $-910,900$ & $-1,938,900$ & $-2,537,400$ \\
\hline
\end{tabular}

The largest effects are observed in the ZE scenario (total: savings of 19 million $€$ p.a.) with similar monetary effects from the two sources each, changes in air quality ( 9.8 million $€$ ) and changes in physical activity $(9.2$ million $€$ ). In addition, Table 9 shows a range of intangible costs due to increased 
health and avoided deaths relative to the baseline. Depending on the VOLY unit saved costs account for 350 to 740 million $€$ or 490 to 1026 million $€$ (from GM to ZE scenario). Applying the VSL shows total values which are higher by the factor 2 to 3 . Note, that even the most conservative of these valuations for both the GE and ZE scenarios indicate intangible benefits arising from these policies in just these three cities that are equivalent to $0.25 \%$ of overall Austrian GDP.

\subsubsection{Macroeconomic Effects}

The national macroeconomic impacts arise from changes in private and public expenditures for mobility (consumption and investment) and from changes in health expenditures funded by public authorities. Additionally, there are macroeconomic effects due to changes in work absence and morbidity leading to increases in productivity of the labor force. Changes in mortality have not been considered in the CGE model. Note that changes in private consumption are implemented by means of changes in the underlying utility function of the representative household. We thus assume that utility before and after the change in transport demand stays constant, but at different (lower) cost.

Figure 10 summarizes the macroeconomic effects. The most important finding is that for all scenarios there are welfare gains, ranging between $+0.15 \%$ and $+0.25 \%$, with the strongest effect in the Green Exercise scenario. The relatively strong positive welfare effect is a result of changes in private consumption. Private households spend less on mobility, while their utility derived from mobility remains constant. On the macroeconomic level the welfare level thus increases. The effect on GDP, however, is slightly negative and correlates with the effects on the labor market. This is due to a shift of private and public expenditures from relatively labor-intensive goods and services (sale of cars, repair of conventional cars) to capital intensive goods (public transport infrastructure, rolling stock). The unemployment rate thus increases in all scenarios between $0.05 \%$ to $0.1 \%$ points, causing negative impacts on GDP. This effect is strongest in the ZE scenario, due to the relatively strong decrease in demand for retail and repair of cars with conventional drives as in this scenario all drives have been replaced by electric motors (cars and public transport). When additionally accounting for the intangible benefits as shown in Table 9, the welfare effects are much stronger. Depending on the evaluation method (VOLY or VSL), the welfare effect is between $+0.3 \%$ (GM, VOLY: $43,000 €$ ) and $+1.3 \%$ (ZE, VSL: 1.65 million $€$ ).

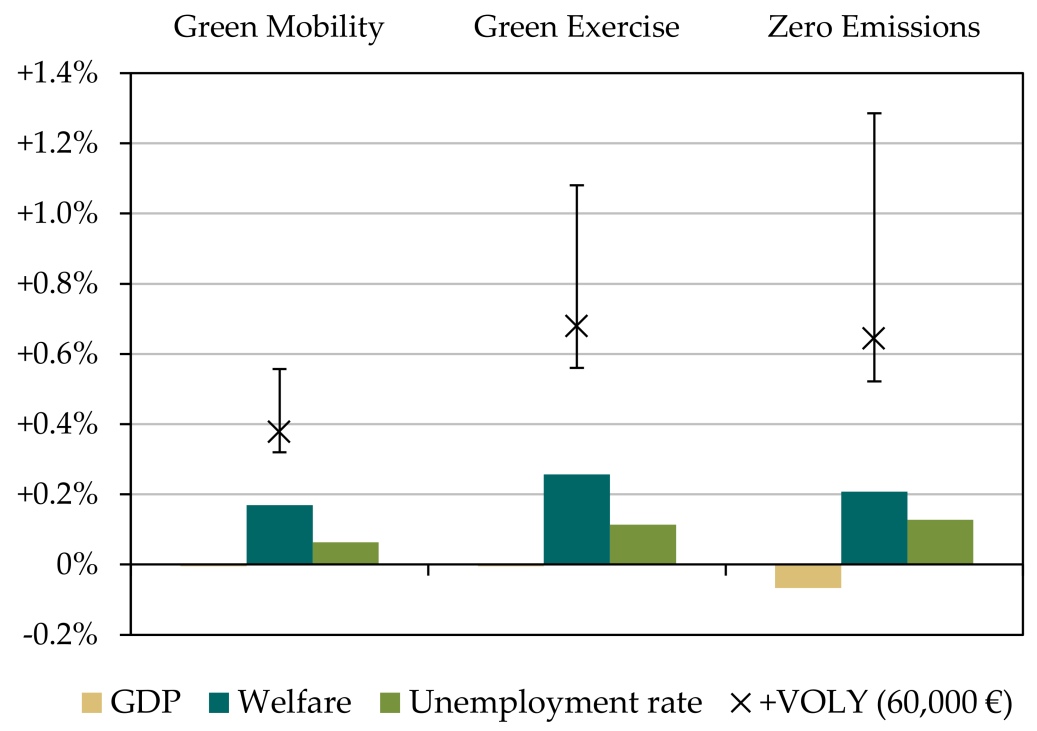

Figure 10. Changes in Gross Domestic Product (GDP), welfare and unemployment for the three scenarios. Error bars indicate welfare effects when additionally accounting for intangible benefits (upper range: using VSL approach with 1.65 million $€$ per life [60]; lower range: using VOLY approach with 43,000 €/VOLY [58]). 
Decomposing the total macroeconomic changes of GDP, welfare and unemployment shows the contribution for the different cost components private expenditures, public expenditures (investment and operating costs), as well as for changes in labor productivity due to morbidity. Figure 11 shows this decomposition for the Green Exercise scenario.

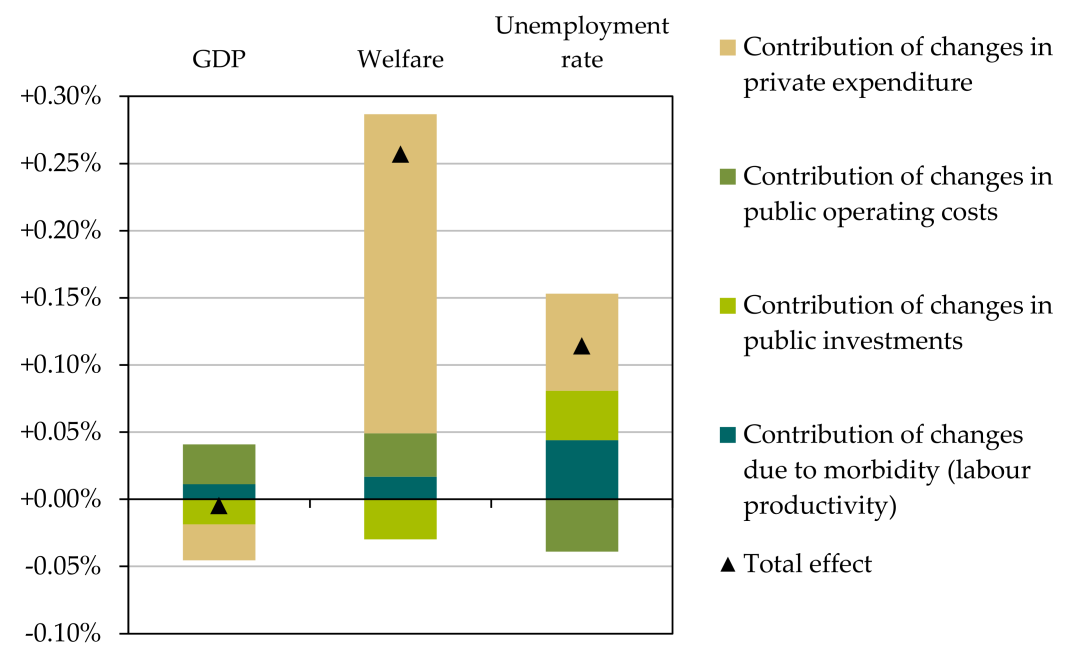

Figure 11. Decomposing the effects of climate mitigation measures on GDP, welfare and employment (illustrative for the Green Exercise scenario).

The overall positive welfare effect $(+0.25 \%)$ is mainly driven by the decrease in necessary private expenditures, and only to a small extent by changes in public operating costs and morbidity. Shifts in public investment slightly diminish the overall welfare effect, however the total effect is clearly positive. When decomposing the GDP effect, we see that shifts in public operating costs and decreased morbidity enter positively into the GDP effect, while the changes in the composition of the public investment structure and private expenditure structure reduce this effect leading to an overall neutral effect on GDP. Regarding unemployment, we find that the changes in the structure of public and private expenditures and decreased morbidity lead to an increase in the unemployment rate while operating costs (e.g., staff for public transport) decreases unemployment.

\subsection{Summary of Results}

If the city governments of Vienna, Graz and Linz (about 2 million inhabitants) implement their already ambitious plans for passenger transport, as modeled in the Green Mobility scenario, this would lead to a $25 \%$ reduction of GHG emissions from passenger transport (minus $0.3 \mathrm{Mt} \mathrm{CO}_{2} \mathrm{equ}$ ) and about 550 deaths due to better air quality and more physical exercise.

If city governments were to intensify the measures, especially with regard to health improvements, it would be a worthwhile-although politically challenging - endeavor, as $44 \%$ of the GHG emissions (minus $0.5 \mathrm{Mt} \mathrm{CO} 2 \mathrm{equ}$ ) can be reduced. Due to a further reduced risk of death, the number of deaths decreases by 1200 compared to the baseline.

If, as has already been discussed, combustion engines will be replaced by electric engines as in the Zero Emission scenario, further GHG emissions reductions can be achieved. Particulate matter produced by means of abrasion and resuspension remain, while particulates due to combustion disappear, as well as emissions of $\mathrm{NO}_{2}$. $\mathrm{CO}_{2}$ equ emissions disappear completely (reduction of about 1

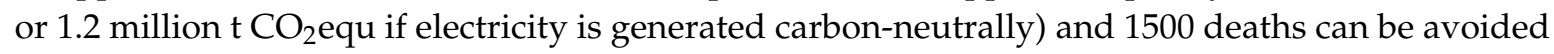
relative to the baseline (displayed separately in Table 10 for air quality and physical activity).

Valuated in monetary terms, health benefits account for up to 11 million $€$ relative to the baseline per year. Additional costs for implementation and operation of public transport and bike or pedestrian facilities are mostly compensated by saved costs for motorized individual transport. For the Green 
Mobility and Green Exercise Scenario, costs are mainly borne by the public sector while benefits are generated by private households. For the Zero Emission scenario, additional costs for e-cars are borne by private households who are, however, compensated by benefits due to the switch from combustion to electric engines. If intangible costs (VSL) are included health co-benefits are substantially higher by a factor around 100 .

Table 10. Co-benefits of climate mitigation in urban transportation for the three scenarios and cities.

\begin{tabular}{lccc}
\hline \multicolumn{1}{c}{ Summary of co-benefits } & Green Mobility & Green Exercise & Zero Emissions \\
\hline Mortality (death cases) & & & \\
$\quad$ Air Quality & -135 & -284 & -647 \\
$\quad$ Physical Activity & -417 & -891 & -891 \\
$\begin{array}{l}\text { GHG emissions } \\
\quad\left(t \text { CO }_{2} \text { equ }\right)\end{array}$ & $-289,680$ & $-534,260$ & $-956,500$ \\
$\begin{array}{l}\text { Direct and indirect health costs } \\
\quad(1000 € \text { per year) }\end{array}$ & $-11,800$ & $-18,000$ & $-19,000$ \\
$\quad$ Intangible costs VSL & $-910,900$ & $-1,938,900$ & $-2,537,400$ \\
$\quad(1000 €$ per year) & $-0.01 \%$ & $-0.00 \%$ & $-0.07 \%$ \\
Macroeconomic Effects [\%] & $+0.2 \%$ & $+0.3 \%$ & $+0.2 \%$ \\
$\quad$ GDP & $+0.1 \%$ & $+0.1 \%$ & $+0.1 \%$ \\
$\quad$ Welfare & & & \\
$\quad$ Employment & & & \\
\hline
\end{tabular}

Macroeconomic effects on gross domestic product (GDP) are weakly negative and strongly affected by a slightly lowered employment rate and by reduced health spending. However, for all scenarios, the increase in welfare is between $+0.2 \%$ and $+0.3 \%$. The relatively strong positive welfare effect is mainly due to an increase in free disposable income, as private households can still meet their mobility needs with lower expenditures.

Figure 12 shows a summary of results per 100,000 inhabitants. For the Zero Emissions Scenario with a carbon neutral power mix this yields a reduction of about $60,000 \mathrm{t}$ of $\mathrm{CO}_{2}$ equ relative to the baseline, a reduction of about 75 death cases and cost savings, i.e., benefits of $940,000 €$ per 100,000 inhabitants and year.

\section{Reduced mortality and saved $\mathrm{CO}_{2} \mathrm{equ}$ per 100,000 inhabitants}

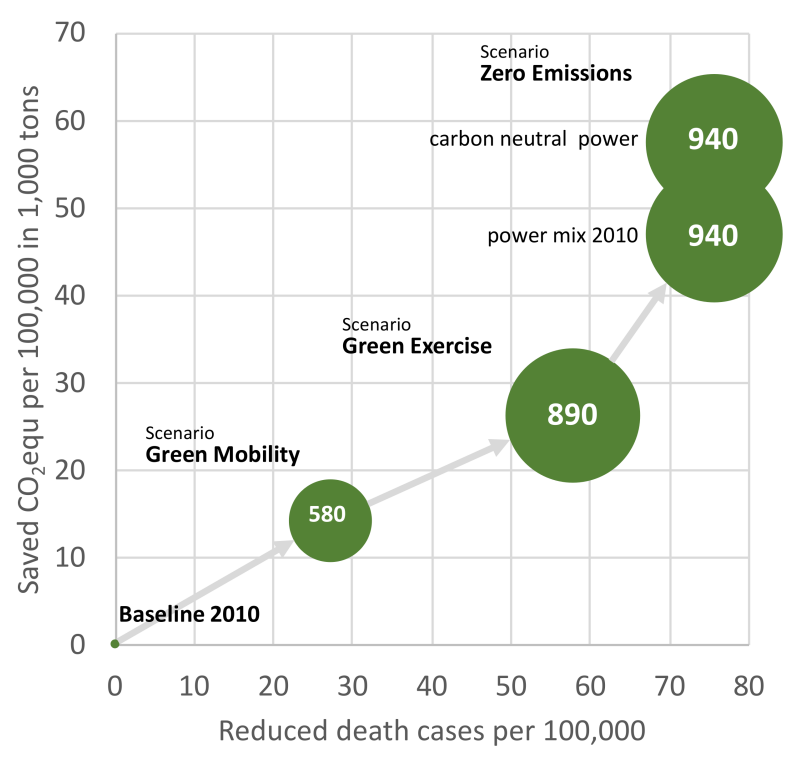

Figure 12. Summary of co-benefits due to $\mathrm{CO}_{2}$ equ reduction, reduced death cases (through physical activity and improved air quality) and reduced health costs. The size of the green bubbles correspond to the numbers in white which represent the cost savings due to mortality and morbidity decreases for each scenario in $1000 € / 100,000$ inhabitants. 


\section{Discussion}

Recent literature shows positive health co-benefits from improved air quality and physical activity due to climate mitigation strategies in passenger transport (cf. $[10,12])$. Most of the studies end with the valuation of changes in health parameters (deaths, incidence, hospital admissions etc.) and do not include an economic assessment of these benefits in monetary terms. Some consider specific aspects like changes in air quality or cycling only to be considered [13]. There is only one study incorporating investment and operating costs of transportation policies, which are compared with benefits [21]. A reason for the lack of economic valuation could be that valuation of co-benefits needs an interplay of different disciplines and model approaches, which is a challenging task. It calls for a mutual understanding of different disciplines and models and well-considered interfaces between the models and corresponding data. As an example, some models (in our case the emission dispersion model) take many weeks to generate spatially-explicit air pollution data. Thus, only few changes in input data can cause time-consuming and costly interdependent model runs. Furthermore, a wide set of data from different sources has to be collected and processed on different levels of detail.

By conducting the underlying study, we meet these challenges despite the expected obstacles and apply a multi-model approach that considers all modes of passenger transport (cycling, walking, public transport and car travel). We consider and model commuters transport (within the city borders). Our approach regards and valuates direct investment and operating costs of mitigation policies as well as monetarized benefits from reduced health costs for private households and the public sector. Furthermore, the approach incorporates a macroeconomic feedback analysis of indirect costs and benefits due to the interrelation of different sectors within the national economy.

Jack and Kinney [70] emphasize that available estimates of co-benefits have only rarely found their way into policy considerations and suggest retrospective analysis instead of future modelling to enhance credibility of results. With this study we take an alternative route to this challenge by starting from the passenger transport targets as agreed to by city parliaments and calculate the health co-benefits of these mitigation policies. Further, we put high emphasis in enhancing the measures especially in those areas where high health benefits are to be expected to provide environmental policy makers an additional health incentive for increasing their effort.

Our results show that this effort is worthwhile because benefits from reduced death and incidence cases occur for all scenarios, as well as substantial decreases of $\mathrm{CO}_{2}$ equ emissions and remarkable health cost savings per year. The macroeconomic analysis shows weakly negative effects for employment and GDP but positive effects on welfare. Especially when accounting for intangible dimensions, the evaluated co-benefits can compensate the potential economy-wide welfare losses from climate change impacts in Austria, which have been monetized recently in a comprehensive climate change impact assessment [71].

Still, it can be assumed that results represent an underestimation due to lack of data or appropriateness of modelling. These include psychological benefits due to more physical activity, reduced noise, increased social interaction (e.g., when switching from car to public transport) or increased green spaces (when sealed areas are rebuilt as is included in the scenarios). Such further aspects have been evaluated e.g., by Mueller et al. [1], de Nazelle et al. [72] and Boniface et al. [73]. By using qualitative methods like systematic surveys, the assessment of these costs and benefits could be amended. A further underestimation occurs because climate and congestion costs have not been included in the study. Noise costs include health costs and costs of annoyance. Applying an average cost factor per passenger-km [74] of $1.7 €$ per $1000 \mathrm{p}-\mathrm{km}$ would yield cost savings of 3 to 5.5 million $€$ a year. The same procedure for external climate costs leads to cost savings that would range from 5 to 30 million $€$ per year for the GM scenario and 10 to 55 million $€$ per year for the GE and ZE scenario depending on the climate change scenario. Due to these uncertainties, broad ranges of cost factors not including specific spatial distribution, infrastructure conditions and exposure to the population these numbers were not included in the result tables. Further research could be done by using specific data from NEMO to calculate spatially specific changes of noise and merging these results with 
population data. The value of statistical life (VSL) or the value of a life year (VOLY) is mostly done by Willingness-to-Pay analysis, which is seen to be of considerably varying results (cf. Xia et al., [12]). However we included the VOLY concept in our analysis to depict the intangible costs. As we based our calculations on the YLL and YLD values which were not available for all diseases, changes in intangible costs can be seen as the lower bound. While there are increasing voices that clearly think that the VOLY concept is more meaningful in the context of air quality $[57,58,75]$ other studies still apply the VSL approach [76,77]. Bollen et al. [77] argue that the VSL would follow the precautionary principle and would be statistically more reliable. We therefore applied two VOLY factors and contrasted them to the VSL results. Changes in morbidity and sick leaves are also considered in the Macroeconomic Model (5) depicting their implications on GDP, employment and welfare.

Another limitation of the approach presented is that we do not consider simultaneous changes in other health-related aspects. Within the broader research effort that this analysis was embedded in, health effects of changed dietary behavior (to foster greenhouse gas mitigation) have also been evaluated. Including combined health effects due to diet and mobility behavioral changes could be subject of future research.

\section{Conclusions}

Modelling co-benefits of mitigation policies in the transportation sector is a complex process requiring the interplay of different disciplines and sensible handling of data. The present study demonstrates that it is worth expanding the effort in quantifying such co-benefit effects of greenhouse gas emission mitigation policies. We do so for the three biggest Austrian urban areas. We directly transfer policy decisions (mitigation targets set by the local governments) into changes in physical activity and air quality and provide information on investment and operating costs but also on health co-benefits from reduced deaths and diseases covering reduced direct and indirect health costs) as well as on macroeconomic effects. As complex economic assessment tools had previously only been employed mainly for measures in the area of cycling (HEAT model [18]) or for changes in air quality [13], this study amends current literature by applying a multi-model comprehensive approach to calculate co-benefits from the perspectives of different economic actors, regarding all modes of passenger transport as well as domestic and commuter transport. Results show remarkable reductions of deaths in the cities, with stronger effects due to increased physical activity than to improvement of air quality. The benefits are highest for the Zero Emission Scenario and are especially due to reductions in $\mathrm{NO}_{2}$ when replacing the entire current vehicle fleet with electric vehicles. Benefits tend to be even higher when additional components would be included, such as changes in psychological effects from increased physical activity, green space or decreased noise exposure due to reduced motorized private transport. We also find that from a macroeconomic perspective, greenhouse gas mitigation policies in urban passenger transport clearly induce a strong positive welfare effect, when also accounting for co-benefits. These effects are remarkably higher when including the reduction of intangible costs, i.e., considering that transport policy due to its health effects is extending life expectancy which we also quantify in monetary terms by means of the value of life years (VOLY). We conclude that it is worthwhile to make the effort to assess co-benefits of climate mitigation policies in urban areas, because the numbers are significant and warrant consideration in decision making.

Supplementary Materials: The following are available online at http:/ /www.mdpi.com/1660-4601/15/5/880/s1, Supplementary Material for Models.

Author Contributions: W.H., K.W.S. and U.W. conceived the project idea and contributed substantially to the paper writing. B.M., P.M., W.H. conceived and designed the Transport Modelling Tool, R.R. the Dispersion Model. H.-P.H. reviewed and compiled the relative risks and J.D. and R.G. designed the Austrian Health Model. G.B. designed the CGE-model and contributed the macroeconomic results and wrote on the paper. B.W. conceived and designed the Economic Assessment Tool and the Transport Modelling Tool and contributed substantially to the paper writing.

Acknowledgments: This work was financed by the Austrian Climate and Energy Fund through the research (ACRP6-ClimBHealth: Climate and health co-benefits from changes in urban mobility and diet: an integrated 
assessment for Austria-KR13AC6K10969 and SHIFT: Policy shift for the low-carbon transition in a globally embedded economy-KR16AC0K13367).

Conflicts of Interest: The authors declare no conflict of interest.

\section{Appendix A}

Table A1. Sector description of CGE model.

\begin{tabular}{|c|c|c|}
\hline NACE Code & Activity/Industry & Model Code \\
\hline V01 & Crop and animal production, hunting and related service activities & AGRI \\
\hline V02 & Forestry and logging & FORE \\
\hline V86 & Human health activities & \multirow{2}{*}{ HEAL } \\
\hline V87_88 & Residential care activities; Social work activities without accommodation & \\
\hline V36 & Water collection, treatment and supply & WATE \\
\hline V37_39 & $\begin{array}{l}\text { Sewerage; Waste collection, treatment and disposal activities; materials recovery; } \\
\text { Remediation activities and other waste management services }\end{array}$ & WAST \\
\hline V35 & Electricity, gas, steam and air conditioning supply & ELEC \\
\hline V19 & Manufacture of coke and refined petroleum products & COKE \\
\hline V28 & $\begin{array}{l}\text { Manufacture of machinery and equipment n.e.c.; Manufacture of electrical } \\
\text { equipment }\end{array}$ & $\mathrm{MACH}$ \\
\hline V29 & Manufacturing of cars & MACA \\
\hline V30 & Manufacture of other transport equipment & MAVE \\
\hline V41 & Construction of buildings & BUIL \\
\hline $\mathrm{V} 42$ & Civil engineering & CIEN \\
\hline V43 & Specialised construction activities & CONT \\
\hline V68 & Real estate activities & REAL \\
\hline V71 & Architectural and engineering activities; technical testing and analysis & $\mathrm{ARCH}$ \\
\hline V45 & Wholesale and retail trade and repair services of motor vehicles and motorcycles & TRCA \\
\hline V49 & Land transport and transport via pipelines & LTRA \\
\hline V50 & Water transport & WTRA \\
\hline V51 & Air transport & ATRA \\
\hline V52_53 & $\begin{array}{l}\text { Warehousing and support activities for transportation; Postal and courier } \\
\text { activities }\end{array}$ & STRA \\
\hline V10, V12 & Manufacture of food products; Manufacture of tobacco products & FOOD \\
\hline V11 & Manufacture of beverages & BEVE \\
\hline V16 & $\begin{array}{l}\text { Manufacture of wood and of products of wood and cork, except furniture; } \\
\text { manufacture of articles of straw and plaiting materials }\end{array}$ & WOOD \\
\hline V17 & Manufacture of paper and paper products & PAPE \\
\hline V20 & Manufacture of chemicals and chemical products & CHEM \\
\hline V21 & Manufacture of basic pharmaceutical products and pharmaceutical preparations & PHAR \\
\hline V22_23 & $\begin{array}{l}\text { Manufacture of rubber and plastic products; Manufacture of other non-metallic } \\
\text { mineral products }\end{array}$ & PLAS \\
\hline V24 & Manufacture of basic metals & META \\
\hline V25 & Manufacture of fabricated metal products, except machinery and equipment & MAME \\
\hline V27 & Manufacture of electrical equipment; & MAEL \\
\hline $\begin{array}{l}\text { V13_14, V18, } \\
\text { V26, V31_33 }\end{array}$ & $\begin{array}{l}\text { Rest of manufacturing (Manufacture of textiles; Manufacture of wearing apparel; } \\
\text { Printing and reproduction of recorded media; Manufacture of computer, } \\
\text { electronic and optical products; Manufacture of furniture; Other manufacturing; } \\
\text { Repair and installation of machinery and equipment) }\end{array}$ & RMAN \\
\hline V15 & Manufacture of leather and related products & LEAT \\
\hline V46_47 & $\begin{array}{l}\text { Wholesale trade, except of motor vehicles and motorcycles; Retail trade, except } \\
\text { of motor vehicles and motorcycles }\end{array}$ & TRAD \\
\hline
\end{tabular}


Table A1. Cont.

\begin{tabular}{|c|c|c|}
\hline NACE Code & Activity/Industry & Model Code \\
\hline V64 & Financial service activities, except insurance and pension funding & FINA \\
\hline V65 & Insurance, reinsurance and pension funding, except compulsory social security & INSU \\
\hline V66 & Activities auxiliary to financial services and insurance activities & AFIN \\
\hline V84 & Public administration and defence; compulsory social security & PUBL \\
\hline V55_56 & Accommodation; Food and beverage service activities & $\mathrm{ACCO}$ \\
\hline V79 & Travel agency, tour operator and other reservation service and related activities & TRAV \\
\hline V90 & Creative, arts and entertainment activities & ENTE \\
\hline V91 & Libraries, archives, museums and other cultural activities & CULT \\
\hline V93 & Sports activities and amusement and recreation activities & SPOR \\
\hline V03, V05_09 & $\begin{array}{l}\text { Fishing and aquaculture; Mining of coal and lignite, Extraction of crude } \\
\text { petroleum and natural gas, Mining of metal ores, Other mining and quarrying, } \\
\text { Mining support service activities }\end{array}$ & REXT \\
\hline V58 & Publishing activities & \multirow{3}{*}{ RECR } \\
\hline V59_60 & $\begin{array}{l}\text { Motion picture, video and television programme production, sound recording } \\
\text { and music publishing activities; Programming and broadcasting activities }\end{array}$ & \\
\hline V92 & Gambling and betting activities & \\
\hline V69_70 & $\begin{array}{l}\text { Legal and accounting activities; Activities of head offices, management } \\
\text { consultancy activities }\end{array}$ & \multirow{3}{*}{ SCIE } \\
\hline V72 & Scientific research and development & \\
\hline V74_75 & Other professional, scientific and technical activities; Veterinary activities & \\
\hline V61 & Telecommunications & \multirow{2}{*}{ TELE } \\
\hline V62_63 & $\begin{array}{l}\text { Computer programming, consultancy and related activities; Information service } \\
\text { activities }\end{array}$ & \\
\hline V77 & Rental and leasing activities & \multirow{8}{*}{ RSER } \\
\hline V78 & Employment activities & \\
\hline V80_82 & $\begin{array}{l}\text { Security and investigation activities; Services to buildings and landscape } \\
\text { activities; Office administrative, office support and other business support } \\
\text { activities }\end{array}$ & \\
\hline V85 & Education & \\
\hline V94 & Activities of membership organisations & \\
\hline V96 & Other personal service activities & \\
\hline V97_98 & $\begin{array}{l}\text { Activities of households as employers of domestic personnel; Undifferentiated } \\
\text { goods- and services-producing activities of private households for own use }\end{array}$ & \\
\hline V99 & Activities of extraterritorial organisations and bodies & \\
\hline V73 & Advertising and market research & ADVE \\
\hline V95 & Repair of computers and personal and household goods & REPA \\
\hline
\end{tabular}

\section{References}

1. Mueller, N.; Rojas-Rueda, D.; Basagaña, X.; Cirach, M.; Cole-Hunter, T.; Dadvand, P.; Donaire-Gonzalez, D.; Foraster, M.; Gascon, M.; Martinez, D.; et al. Urban and Transport Planning Related Exposures and Mortality: A Health Impact Assessment for Cities. Environ. Health Perspect. 2016, 125. [CrossRef] [PubMed]

2. Perez, L.; Trüeb, S.; Cowie, H.; Keuken, M.P.; Mudu, P.; Ragettli, M.S.; Sarigiannis, D.A.; Tobollik, M.; Tuomisto, J.; Vienneau, D.; et al. Transport-related measures to mitigate climate change in Basel, Switzerland: A health-effectiveness comparison study. Environ. Int. 2015, 85, 111-119. [CrossRef] [PubMed]

3. Woodcock, J.; Givoni, M.; Morgan, A.S. Health Impact Modelling of Active Travel Visions for England and Wales Using an Integrated Transport and Health Impact Modelling Tool (ITHIM). PLoS ONE 2013, 8, e51462. [CrossRef] [PubMed] 
4. Rojas-Rueda, D.; de Nazelle, A.; Tainio, M.; Nieuwenhuijsen, M.J. The health risks and benefits of cycling in urban environments compared with car use: Health impact assessment study. BMJ 2011, 343, d4521. [CrossRef] [PubMed]

5. Haines, A.; McMichael, A.J.; Smith, K.R.; Roberts, I.; Woodcock, J.; Markandya, A.; Armstrong, B.G.; Campbell-Lendrum, D.; Dangour, A.D.; Davies, M.; et al. Public health benefits of strategies to reduce greenhouse-gas emissions: Overview and implications for policy makers. Lancet 2009, 374, 2104-2114. [CrossRef]

6. Woodcock, J.; Edwards, P.; Tonne, C.; Armstrong, B.G.; Ashiru, O.; Banister, D.; Beevers, S.; Chalabi, Z.; Chowdhury, Z.; Cohen, A.; et al. Public health benefits of strategies to reduce greenhouse-gas emissions: Urban land transport. Lancet 2009, 374, 1930-1943. [CrossRef]

7. IPCC Summary for Policymakers. Climate Change 2014: Mitigation of Climate Change. Contribution of Working Group III to the Fifth Assessment Report of the Intergovernmental Panel on Climate Change; Edenhofer, O., Pichs-Madruga, R., Sokona, Y., Farahani, E., Kadner, S., Seyboth, K., Adler, A., Baum, I., Brunner, S., Eickemeier, P., et al., Eds.; Cambridge University Press: Cambridge, UK; New York, NY, USA, 2014.

8. Umweltbundesamt Hintergrundinformation-Treibhausgas-Bilanz 2016; Umweltbundesamt: Wien, Austria, 2017.

9. Umweltbundesamt Ueberschreitungen 2017. Available online: http://www.umweltbundesamt. at/umweltsituation/luft/luftguete_aktuell/ueberschreitungen/ueberschreitungen_2017/ (accessed on 23 January 2018).

10. Quam, V.; Rocklöv, J.; Quam, M.; Lucas, R. Assessing Greenhouse Gas Emissions and Health Co-Benefits: A Structured Review of Lifestyle-Related Climate Change Mitigation Strategies. Int. J. Environ. Res. Public Health 2017, 14, 468. [CrossRef] [PubMed]

11. Shaw, C.; Hales, S.; Howden-Chapman, P.; Edwards, R. Health co-benefits of climate change mitigation policies in the transport sector. Nat. Clim. Chang. 2014, 4, 427-433. [CrossRef]

12. Xia, T.; Zhang, Y.; Crabb, S.; Shah, P. Cobenefits of Replacing Car Trips with Alternative Transportation: A Review of Evidence and Methodological Issues. J. Environ. Public Health 2013, 2013. [CrossRef] [PubMed]

13. Grabow, M.L.; Spak, S.N.; Holloway, T.; Stone, B.; Mednick, A.C.; Patz, J.A. Air Quality and Exercise-Related Health Benefits from Reduced Car Travel in the Midwestern United States. Environ. Health Perspect. 2011, 120, 68-76. [CrossRef] [PubMed]

14. Lindsay, G.; Macmillan, A.; Woodward, A. Moving urban trips from cars to bicycles: Impact on health and emissions. Aust. N. Z. J. Public Health 2011, 35, 54-60. [CrossRef] [PubMed]

15. Maizlish, N.; Woodcock, J.; Co, S.; Ostro, B.; Fanai, A.; Fairley, D. Health Cobenefits and Transportation-Related Reductions in Greenhouse Gas Emissions in the San Francisco Bay Area. Am. J. Public Health 2013, 103, 703. [CrossRef] [PubMed]

16. Holm, A.L.; Glümer, C.; Diderichsen, F. Health Impact Assessment of increased cycling to place of work or education in Copenhagen. BMJ Open 2012, 2, e001135. [CrossRef] [PubMed]

17. Remais, J.V.; Hess, J.J.; Ebi, K.L.; Markandya, A.; Balbus, J.M.; Wilkinson, P.; Haines, A.; Chalabi, Z. Estimating the Health Effects of Greenhouse Gas Mitigation Strategies: Addressing Parametric, Model, and Valuation Challenges. Environ. Health Perspect. 2014. [CrossRef]

18. Rutter, H.; Cavill, N.; Kahlmeier, S.; Racioppi, F.; Oja, P. Health Economic Assessment Tool for Cycling (HEAT for cycling) User guide Version 2; WHO Regional Office for Europe: Copenhagen, Denmark, 2008.

19. Doll, C.; Hartwig, J.; Senger, F. The Private and Public Economics of Sustainable Mobility Patterns. In Proceedings of the 13th WCTR Conference, Rio De Janeiro, Brazil, 15-18 July 2013.

20. Keogh-Brown, M.; Jensen, H.T.; Smith, R.D.; Chalabi, Z.; Davies, M.; Dangour, A.; Edwards, P.; Garnett, T.; Givoni, M.; Griffiths, U.; et al. A whole-economy model of the health co-benefits of strategies to reduce greenhouse gas emissions in the UK. Lancet 2012, 380, S52. [CrossRef]

21. Jensen, H.T.; Keogh-Brown, M.R.; Smith, R.D.; Chalabi, Z.; Dangour, A.D.; Davies, M.; Edwards, P.; Garnett, T.; Givoni, M.; Griffiths, U.; et al. The importance of health co-benefits in macroeconomic assessments of UK Greenhouse Gas emission reduction strategies. Clim. Chang. 2013, 121, 223-237. [CrossRef] [PubMed]

22. Hiess, H. Masterplan Verkehr Wien 2003 Evaluierung 2013; Werkstattbericht; Stadt Wien: Wien, Austria, 2013.

23. Fallast, K.; Moser, M.; Eder, E.; Tischler, G. Regionales Verkehrskonzept Graz und Graz-Umgebung; Das Land Steiermark: Graz, Austria, 2010.

24. City of Graz Mobilitätsstrategie der Stadt Graz; City of Graz: Graz, Austria, 2012. 
25. Sammer, G.; Röschel, G.; Gruber, C. Gesamtverkehrskonzept für den Großraum Linz, Verkehrspolitische Leitlinien-Maßnahmenprogramm; Auftraggeber und Projektleitung: Linz/Graz/Wien, Austria, 2012.

26. IPCC Climate Change 2014 Synthesis Report Summary for Policymakers. In Climate Change 2014: Impacts, Adaptation, and Vulnerability. Part A: Global and Sectoral Aspects. Contribution of Working Group II to the Fifth Assessment Report of the Intergovernmental Panel on Climate Change; Edenhofer, O.; Pichs-Madruga, R.; Sokona, Y.; Farahani, E.; Kadner, S.; Seyboth, K.; Adler, A.; Baum, I.; Brunner, S.; Eickemeier, P.; et al. (Eds.) Cambridge University Press: Cambridge, UK; New York, NY, USA, 2014.

27. Statistics Austria Economically Active Persons by Category and Distance. Available online: http:/ / www.stat.at/web_en/statistics/PeopleSociety/population/population_censuses_register_ based_census_register_based_labour_market_statistics/commuters/index.html (accessed on 4 March 2017).

28. Rexeis, M.; Hausberger, S. Calculation of Vehicle Emissions in Road Networks with the model "NEMO.". In Proceedings of the 85/I 14th Symposium Transport and Air Pollution, Graz, Austria, 1-3 June 2005; pp. 118-127.

29. Oettl, D. Documentation of the Lagrangian Particle Model GRAL, Graz Lagrangian Model Vs. 13.3; Amt der Steiermärkischen Landesregierung, FA17C; Technische Umweltkontrolle: Graz, Austria, 2013.

30. Bachler, G.; Karner, M.; Kurz, C.; Reifeltshammer, R.; Sturm, P. Modellierung von Verkehrsszenarien im Rahmen des ACRP—Projektes ClimbHealth; IVT I-05/16/Ku V\&U I-14/13/630 V3.0; IVT-TUGRAZ: Graz, Austria, 2016.

31. Arem, H.; Moore, S.C.; Patel, A.; Hartge, P.; Berrington de Gonzalez, A.; Visvanathan, K.; Campbell, P.T.; Freedman, M.; Weiderpass, E.; Adami, H.O.; et al. Leisure Time Physical Activity and Mortality: A Detailed Pooled Analysis of the Dose-Response Relationship. JAMA Intern. Med. 2015, 175, 959. [CrossRef] [PubMed]

32. Kelly, P.; Kahlmeier, S.; Götschi, T.; Orsini, N.; Richards, J.; Roberts, N.; Scarborough, P.; Foster, C. Systematic review and meta-analysis of reduction in all-cause mortality from walking and cycling and shape of dose response relationship. Int. J. Behav. Nutr. Phys. Act. 2014, 11. [CrossRef] [PubMed]

33. Woodcock, J.; Franco, O.H.; Orsini, N.; Roberts, I. Non-vigorous physical activity and all-cause mortality: Systematic review and meta-analysis of cohort studies. Int. J. Epidemiol. 2011, 40, 121-138. [CrossRef] [PubMed]

34. Bull, F.C.; Armstrong, T.P.; Dixon, T.; Ham, S.; Neiman, A.; Pratt, M. Physical inactivity. In Comparative Quantification of Health Risks Global and Regional Burden of Disease Attributable to Selected Major Risk Factors; Ezzati, M., Lopez, A.D., Rodgers, A., Murray, C.J.L., Eds.; WHO: Geneva, Switzerland, 2004; Volume 1, pp. 729-881.

35. Jetté, M.; Sidney, K.; Blümchen, G. Metabolic equivalents (METS) in exercise testing, exercise prescription, and evaluation of functional capacity. Clin. Cardiol. 1990, 13, 555-565. [CrossRef] [PubMed]

36. Stare, J.; Maucort-Boulch, D. Odds Ratio, Hazard Ratio and Relative Risk. Metodoloski Zv. 2016, $13,59-67$.

37. WHO ICD-10 International statistical classification of diseases and related health problems. Available online: http:/ / www.who.int/classifications/icd/en/ (accessed on 26 January 2018).

38. Statistics Austria Population by Demographic Characteristics. Available online: https://www.statistik. at/web_en/statistics/PeopleSociety/population/population_change_by_demographic_characteristics/ index.html (accessed on 20 February 2018).

39. Statistics Austria Causes of Deaths; STAT: Vienna, Austria, 2018.

40. IHME-Institute for Health Metrics and Evaluation. Global Burden of Disease Study 2015 (GBD 2015) Results; IHME-Institute for Health Metrics and Evaluation: Seattle, WA, USA, 2016.

41. Künzli, N.; Kaiser, R.; Medina, S.; Studnicka, M.; Chanel, O.; Filliger, P.; Herry, M.; Horak, F.; Puybonnieux-Texier, V.; Quénel, P.; et al. Public-health impact of outdoor and traffic-related air pollution: A European assessment. Lancet 2000, 356, 795-801. [CrossRef]

42. Hoek, G.; Krishnan, R.M.; Beelen, R.; Peters, A.; Ostro, B.; Brunekreef, B.; Kaufman, J.D. Long-term air pollution exposure and cardio- respiratory mortality: A review. Environ. Health 2013, 12. [CrossRef] [PubMed]

43. Raaschou-Nielsen, O.; Andersen, Z.J.; Beelen, R.; Samoli, E.; Stafoggia, M.; Weinmayr, G.; Hoffmann, B.; Fischer, P.; Nieuwenhuijsen, M.J.; Brunekreef, B.; et al. Air pollution and lung cancer incidence in 17 European cohorts: Prospective analyses from the European Study of Cohorts for Air Pollution Effects (ESCAPE). Lancet Oncol. 2013, 14, 813-822. [CrossRef]

44. Faustini, A.; Rapp, R.; Forastiere, F. Nitrogen dioxide and mortality: Review and meta-analysis of long-term studies. Eur. Respir. J. 2014, 44, 744-753. [CrossRef] [PubMed] 
45. Cesaroni, G.; Forastiere, F.; Stafoggia, M.; Andersen, Z.J.; Badaloni, C.; Beelen, R.; Caracciolo, B.; de Faire, U.; Erbel, R.; Eriksen, K.T.; et al. Long term exposure to ambient air pollution and incidence of acute coronary events: Prospective cohort study and meta-analysis in 11 European cohorts from the ESCAPE Project. BMJ 2014, 348, f7412. [CrossRef] [PubMed]

46. Vienneau, D.; Perez, L.; Schindler, C.; Lieb, C.; Sommer, H.; Probst-Hensch, N.; Künzli, N.; Röösli, M. Years of life lost and morbidity cases attributable to transportation noise and air pollution: A comparative health risk assessment for Switzerland in 2010. Int. J. Hyg. Environ. Health 2015, 218, 514-521. [CrossRef] [PubMed]

47. Statistics Austria Cancer Incidence, Overview; STAT: Vienna, Austria, 2017.

48. Federal Ministry of Labour. Social Affairs and Consumer Protection Stationäre Aufenthalte (KJ) 2007-2016; Federal Ministry of Labour: Vienna, Austria, 2017.

49. Statistics Austria OENACE 2008-Structure. Available online: http://www.statistik.at/KDBWeb/ kdb_VersionAuswahl.do?FAM=WZWEIG\&NAV=DE\&VersID=10438\&EXT=J\&KDBtoken=? (accessed on 21 February 2018).

50. Statistics Austria Household Budget Survey 2009/2010; STAT: Vienna, Austria, 2011.

51. Hausberger, S. Erstellung globaler Emissionsdaten für Österreichische Kfz von 1950 bis 2030; Technical University of Graz: Graz, Austria, 2010.

52. Jo, C. Cost-of-illness studies: Concepts, scopes, and methods. Clin. Mol. Hepatol. 2014, 20, 327-337. [CrossRef] [PubMed]

53. Walter, E.; Zehetmayr, S. Theoretische Implikationen zur gesundheitsökonomischen Evaluation mit Ausblick auf Österreich. Wien. Med. Wochenschr. 2006, 156, 622-627. [CrossRef] [PubMed]

54. Haucke, F.; Holle, R.; Wichmann, H.E. Epidemiologische Erforschung und ökonomische Bewertung gesundheitlicher Umweltrisiken. Bundesgesundheitsblatt Gesundheitsforschung Gesundheitsschutz 2009, 52, 1166-1178. [CrossRef] [PubMed]

55. Le, C.; Lin, L.; Jun, D.; Jianhui, H.; Keying, Z.; Wenlong, C.; Ying, S.; Tao, W. The economic burden of type 2 diabetes mellitus in rural southwest China. Int. J. Cardiol. 2013, 165, 273-277. [CrossRef] [PubMed]

56. Holland, M. Cost-Benefit Analysis of Final Policy Scenarios for the EU Clean Air Package-Version 2; EMRC: London, UK, 2014.

57. Bickel, P.; Friedrich, R. ExternE: Externalities of Energy: Methodology 2005 Update; Office for Official Publications of the European Communitie: Luxembourg, 2005.

58. Desaigues, B.; Ami, D.; Bartczak, A.; Braun-Kohlová, M.; Chilton, S.; Czajkowski, M.; Farreras, V.; Hunt, A.; Hutchison, M.; Jeanrenaud, C.; et al. Economic valuation of air pollution mortality: A 9-country contingent valuation survey of value of a life year (VOLY). Ecol. Indic. 2011, 11, 902-910. [CrossRef]

59. Statistics Austria Consumer Price Index (CPI 2005). Available online: http://www.statistik.at/web_en/ statistics /Economy / Prices/consumer_price_index_cpi_hcpi/index.html (accessed on 27 March 2018).

60. D 5.3.1/2 Methods and results of the HEIMTSA/INTARESE Common Case Study; University of Stuttgart: Stuttgart, Germany, 2011.

61. Zsifkovits, J. Krankheitsausgabenrechnung für das Jahr 2008 (2012); Gesundheit Österreich: Vienna, Austria, 2012.

62. Alt, R.; Binder, A.; Helmenstein, C.; Kleissner, A.; Krabb, P. Der volkswirtschaftliche Nutzen von Bewegung Volkswirtschaftlicher Nutzen von Bewegung, volkswirtschaftliche Kosten von Inaktivität und Potenziale von mehr Bewegung; SpEA SportsEconAustria: Wien, Austria, 2015.

63. Brown, M.L.; Lipscomb, J.; Snyder, C. The Burden of Illness of Cancer: Economic Cost and Quality of Life. Annu. Rev. Public Health 2001, 22, 91-113. [CrossRef] [PubMed]

64. Leoni, T. Fehlzeitenreport 2011. Krankheits- und unfallbedingte Fehlzeiten in Österreich. In Monographien; WIFO: Vienna, Austria, 2011.

65. Pritchard, C.; Sculpher, M. Productivity Costs: Principles and Practice in Economic Evaluation; Off. of Health Economics: London, UK, 2000; ISBN 978-1-899040-76-6.

66. Bachner, G. Assessing the economy-wide effects of climate change adaptation options of land transport systems in Austria. Reg. Environ. Chang. 2017. [CrossRef]

67. Armington, P.S. A Theory of Demand for Products Distinguished by Place of Production (Une théorie de la demande de produits différenciés d'après leur origine) (Una teoría de la demanda de productos distinguiéndolos según el lugar de producción). Staff Pap. Int. Monet. Fund 1969, 16, 159-178. [CrossRef]

68. Lofgren, H.; Haris, R.L.; Robinson, S. A Standard Computable General Equilibrium (CGE) Model in GAMS; International Food Policy Research Institute: Washington, DC, USA, 2002. 
69. WHO Health Statistics and Information Systems. Available online: http://www.who.int/healthinfo/global_ burden_disease/metrics_daly/en/(accessed on 26 January 2018).

70. Jack, D.W.; Kinney, P.L. Health co-benefits of climate mitigation in urban areas. Curr. Opin. Environ. Sustain. 2010, 2, 172-177. [CrossRef]

71. Bachner, G.; Bednar-Friedl, B.; Nabernegg, S.; Steininger, K.W. Macroeconomic Evaluation of Climate Change in Austria: A Comparison Across Impact Fields and Total Effects. In Economic Evaluation of Climate Change Impacts: Development of a Cross-Sectoral Framework and Results for Austria; Steininger, K.W., König, M., Bednar-Friedl, B., Kranzl, L., Loibl, W., Prettenthaler, F., Eds.; Springer: Berlin, Germany, 2015; pp. 415-440.

72. De Nazelle, A.; Nieuwenhuijsen, M.J.; Antó, J.M.; Brauer, M.; Briggs, D.; Braun-Fahrlander, C.; Cavill, N.; Cooper, A.R.; Desqueyroux, H.; Fruin, S.; et al. Improving health through policies that promote active travel: A review of evidence to support integrated health impact assessment. Environ. Int. 2011, 37, 766-777. [CrossRef] [PubMed]

73. Boniface, S.; Scantlebury, R.; Watkins, S.J.; Mindell, J.S. Health implications of transport: Evidence of effects of transport on social interactions. J. Transp. Health 2015, 2, 441-446. [CrossRef]

74. Van Essen, H.; Schroten, A.; Otten, M.; Sutter, D.; Schreyer, C.; Zandonella, R.; Maibach, M.; Doll, C. External Costs of Transport in Europe Update Study 2008; CE Delft: Delft, The Netherlands, 2011.

75. Rabl, A.; Spadaro, J.; Holland, M. How Much Is Clean Air Worth?: Calculating the Benefits of Pollution Control; Cambridge University Press: Cambridge, UK; New York, NY, USA, 2014.

76. Markandya, A.; Sampedro, J.; Smith, S.J.; Van Dingenen, R.; Pizarro-Irizar, C.; Arto, I.; González-Eguino, M. Health co-benefits from air pollution and mitigation costs of the Paris Agreement: A modelling study. Lancet Planet. Health 2018, 2, e126-e133. [CrossRef]

77. Bollen, J.; van der Zwaan, B.; Brink, C.; Eerens, H. Local air pollution and global climate change: A combined cost-benefit analysis. Resour. Energy Econ. 2009, 31, 161-181. [CrossRef]

(C) 2018 by the authors. Licensee MDPI, Basel, Switzerland. This article is an open access article distributed under the terms and conditions of the Creative Commons Attribution (CC BY) license (http:/ / creativecommons.org/licenses/by/4.0/). 